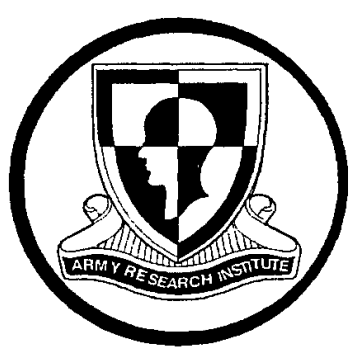

\author{
U.S. Army Research Institute \\ for the Behavioral and Social Sciences
}

Research Report 1830

\title{
Battle Command Visualization 101: \\ Prototype Embedded Training on Networked Sensors
}

Carl W. Lickteig

U.S. Army Research Institute

Charles G. Heiden and William T. Holden, Jr.

Human Resources Research Organization

20050126028

December 2004

Approved for public release; distribution is unlimited. 


\section{U.S. Army Research Institute for the Behavioral and Social Sciences}

\section{A Directorate of the Department of the Army Deputy Chief of Staff, G1}

ZITA M. SIMUTIS
Director

Research accomplished under contract

for the Department of the Army

Human Resources Research Organization

Technical review by

May H. Throne, U.S. Army Research Institute

Robert A. Rasch, Jr., U.S. Army Research Institute

\section{NOTICES}

DISTRIBUTION: Primary distribution of this Research Report has been made by ARI. Please address correspondence concerning distribution of reports to: U.S. Army Research Institute for the Behavioral and Social Sciences, Attn: DAPE-ARI-PO, 2511 Jefferson Davis Highway, Arlington, Virginia 22202-3926

FINAL DISPOSITION: This Research Report may be destroyed when it is no longer needed. Please do not return it to the U.S. Army Research Institute for the Behavioral and Social Sciences.

NOTE: The findings in this Research Report are not to be construed as an official Department of the Army position, unless so designated by other authorized documents. 


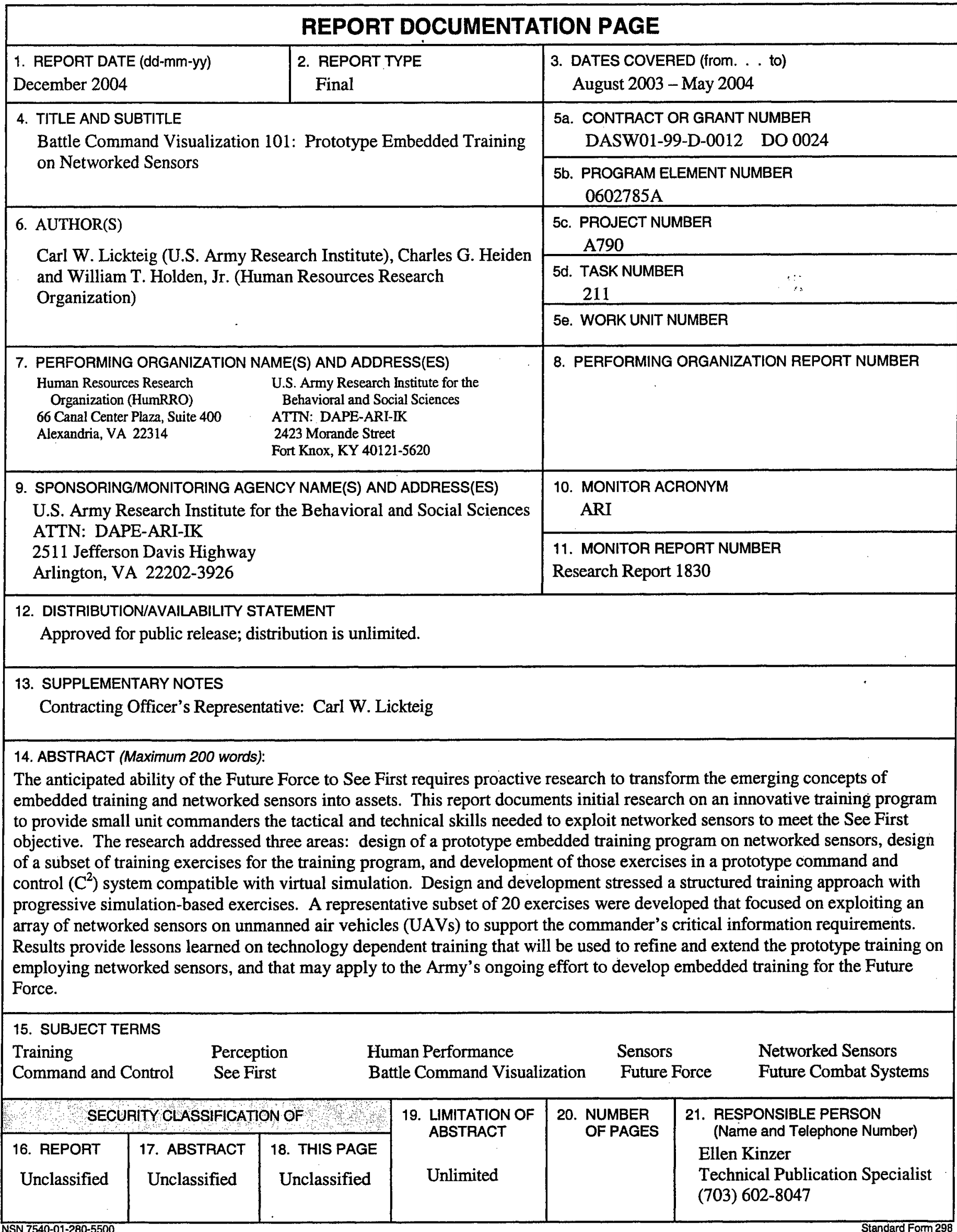


Research Report 1830

\title{
Battle Command Visualization 101: Prototype Embedded Training on Networked Sensors
}

\author{
Carl W. Lickteig \\ U.S. Army Research Institute
}

Charles G. Heiden and William T. Holden, Jr. Human Resources Research Organization

\section{Armored Forces Research Unit \\ Barbara A. Black, Chief}

U.S. Army Research Institute for the Behavioral and Social Sciences 2511 Jefferson Davis Highway, Arlington, Virginia 22202-3926

December 2004 

Innovative training solutions to help the Army transform to the Future Force and Future Combat Systems (FCS) are a key concern of the U.S. Army Research Institute for the Behavioral and Social Sciences (ARI). The Future Battlefield Conditions Team of ARI at Fort Knox is developing a prototype embedded training program to provide small unit commanders the technical and tactical skills to exploit networked sensors. This research supports work package (211) FUTURETRAIN: Techniques and Tools for Command, Control, Communications, Computers, Intelligence, Surveillance, and Reconnaissance Training of Future Brigade Combat Team Commanders and Staffs. This research also supports the Science \& Technology Objective (STO) "Methods and Measures of Commander-Centric Training."

To transition from the Current Force to the Future Force, concepts about the future including embedded training and networked sensors must be investigated efficiently and effectively for utility and development. Small unit commanders in the Current Force have little experience with networked sensors on a regular basis; with the right training, their Future Force counterparts will routinely exploit them.

The research reported here designed a prototype embedded training program for employing networked sensors called Battle Command Visualization (BCV) 101 and developed a representative subset of supporting training exercises. Findings from this initial phase of training development underscore the problems and potential of combining theory and technology for embedded training to support the Future Force, particularly in exploiting networked sensors to See First. An ongoing follow-on effort will extend and refine the BCV 101 training program to provide an exemplar of embedded training for the Future Force.

Results of this ongoing effort were presented to representatives from the Defense Advanced Research Projects Agency and the Program Executive Office for Simulation, Training and Instrumentation for refinement and transition of the BCV 101 training program.

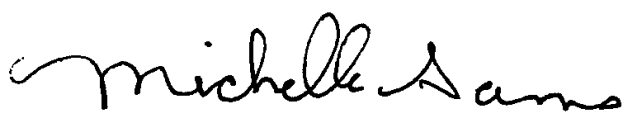

MICHELLE SAMS

Technical Director 


\section{BATTLE COMMAND VISUALIZATION 101: PROTOTYPE EMBEDDED TRAINING ON NETWORKED SENSORS}

\section{EXECUTIVE SUMMARY}

\section{Research Requirement:}

The Army has identified four essential Qualities of Firsts for the Future Force: See First, Understand First, Act First, and Finish Decisively. The Quality of See First forms the foundation for all other Qualities. The requirement to See First rests heavily on proactive research to transform two concepts - networked sensors and embedded training - into assets. Small unit commanders in the Current Force have little experience with networked sensors on a regular basis; with the right training, their Future Force counterparts will routinely exploit them.

This report documents initial research to develop a prototype embedded training program to provide small unit commanders the tactical and technical skills to exploit networked sensors. Because the visualization skills targeted by this research are basic or "101" introductory level skills for battle command visualization (BCV), the training program is referred to as BCV 101 .

Procedure:

The BCV 101 research addressed three areas: design of an embedded training program on employing networked sensors, design of a subset of training exercises for the training program, and development of those exercises in a prototype command and control $\left(\mathrm{C}^{2}\right)$ system compatible with virtual simulation. Program design stressed a structured set of simulation-based exercises nested in a training matrix to systematically control skill progression and assess proficiency through a series of criterion or "gate" exercises.

Exercise design and development focused on a representative subset of exercises to convey an understanding of the capabilities and limitations of networked sensors. A subset of twenty (20) exercises was developed that focused on exploiting an array of networked sensors on unmanned air vehicles (UAVs) to support the commander's critical information requirements. All exercises were initially developed as short-duration (5-10 minute) exercises to maintain a close link between tasks, conditions, and standards, and to provide repeated opportunity for practice and feedback.

During development, the individual exercises were temporarily sorted into exercise bundles to overcome current technical challenges to technology dependent training. All exercises provided simulation-based feedback, including visual depiction of dynamic sensor footprints or coverage areas, automated alerts, and data on sensor detections and sensor images received. Formative evaluations of the exercises with supporting research personnel identified shortcomings in training design and exercise development that will be addressed in follow-on research efforts for BCV 101, and potentially the Army's efforts to develop embedded training in Future Combat Systems. 
Findings:

Overall, the BCV 101 effort provides a promising start on the extended process of developing a working example of embedded training to help meet the See First requirement. The design of the training program and exercises combines theory and technology to address an important and unmet training objective of the Future Force. A follow-on effort is underway to extend and refine BCV 101 training based on lessons learned and challenges encountered. In the interim, this progress report documents current status and provides a set of training implications to further the process of developing embedded training for FCS and the Future Force.

A key finding is that the technical challenges to technology-based training are imposing. This finding may seem obvious, but it is often ignored when future training concepts such as embedded training and simulation-based training are envisioned. In particular, the prototype $\mathrm{C}^{2}$ system linked to virtual simulation did not readily support the training design requirement for minimal turn-around time between exercises. The use of exercise bundles versus discrete exercises provided a near-term workaround to training development, but weakened the training design's links between tasks, conditions, and standards. Technical challenges also limited the ability of the training developers to manipulate and augment feedback on the process and outcomes of sensor employment.

A related finding is that proactive collaboration and research between the developers of training and technology is essential to achieving simulation-based embedded training. A burden on training developers is to provide identified training requirements and proposed training designs to system developers during the earliest stages of system design. A burden on system developers is to modularize the $\mathrm{C}^{2}$ system to permit modifications by training developers. Embedded training guidelines stress the need for a "Training Mode" or module in the $\mathrm{C}^{2}$ system; however, the findings stress that a "Training Development Mode" is also needed.

\section{Utilization of Findings:}

The findings will guide the ongoing follow-on effort to extend and refine the BCV 101 training program. To work around technical challenges, the training design will extend to multimedia and multi-method training approaches. To overcome technical challenges, current and future findings will be provided to the developers of $\mathrm{C}^{2}$ systems for FCS and to the Army's training developers for embedded training. To meet the See First requirement, the BCV 101 training development effort will endeavor to provide the Future Force the right training to exploit networked sensors routinely. 


\section{BATTLE COMMAND VISUALIZATION 101: PROTOTYPE EMBEDDED TRAINING ON NETWORKED SENSORS}

\section{CONTENTS}

Introduction.

Organization of the Report.

Background.

The Quality of "See First" .............................................................................................

Training for See First ........................................................................................................ 2

Sensors in Support of See First............................................................................................ 3

Preliminary Research with Sensors and See First Training ................................................... 5

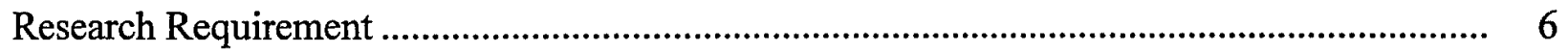

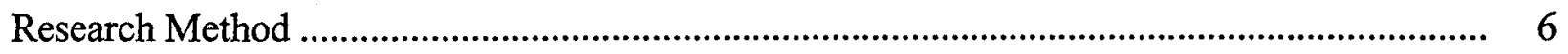

Training Program Design.............................................................................................. 7

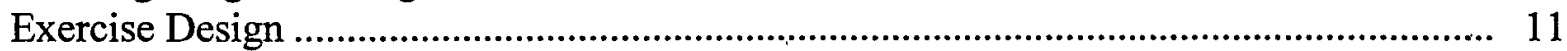

Exercise Development .......................................................................................................... 13

Description of the Command and Control $\left(\mathrm{C}^{2}\right)$ Interface .......................................... 14

Construction of the Sample Exercises ....................................................................... 18

Train-the-Trainer............................................................................................. 19

Major Technical Limitation ................................................................................. 19

Exercise Bundles.......................................................................................... 20

Exercise Overview ................................................................................................ 20

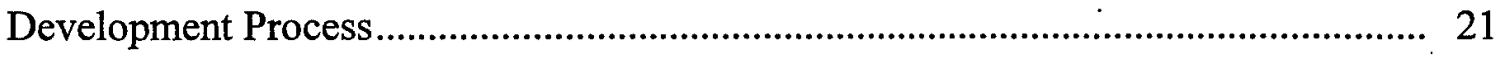

Training Implications......................................................................................................... 24

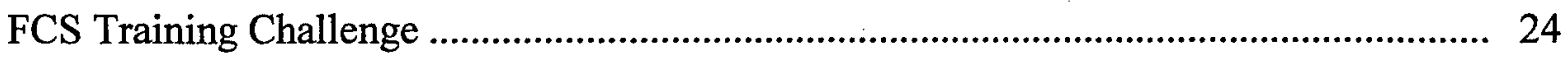

Training Design: Structured Training .............................................................................. 25

Training Development: Technical Collaboration and Authoring Tools ............................. 25

Training Delivery: Simulation-Based Embedded Training ................................................ 27

Training Feedback: Performance Measurement and Perceptual Augmentation................. 28

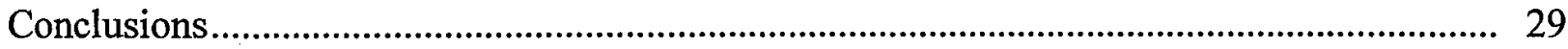


References.

Appendix A Acronyms

Appendix B Prototype Program of Instruction B-1

Appendix C Training Matrix

\section{List of Tables}

Table 1 Overview of Purpose and Approach for Four Modules in the Training

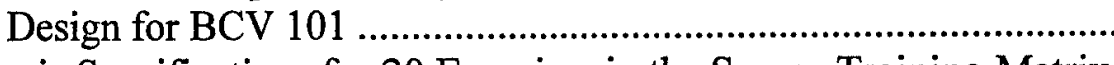

Table 2 Basic Specifications for 20 Exercises in the Sensor Training Matrix ...................... 12

Table 3 Summary of BCV 101 Training Implications........................................................ 24

\section{List of Figures}

Figure 1 Sample of current operational unmanned air vehicles (UAVs)............................. 4

Figure 2 Systematic variations in task conditions for training exercise matrix ..................... 8

Figure 3 Initial sensor training progression matrix...................................................... 8

Figure 4 Command group participants in a surrogate command and control $\left(C^{2}\right)$ vehicle...... 14

Figure 5 Sample view of the command and control $\left(\mathrm{C}^{2}\right)$ interface................................... 15

Figure 6 Command and control $\left(C^{2}\right)$ interface with sensor tasking information.................. 17

Figure 7 Animation snapshot with microUAVs en-route or on-station awaiting next tasking

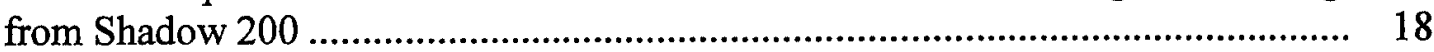

Figure 8 Sample of synthetic aperture radar (SAR) detections ......................................... 22

Figure 9 Command and control $\left(C^{2}\right)$ interface with microUAV sensor image....................... 23

Figure 10 Visual enhancements of sensor coverage and footprint areas ............................. 29 


\title{
BATTLE COMMAND VISUALIZATION 101: PROTOTYPE EMBEDDED TRAINING ON NETWORKED SENSORS
}

\author{
Introduction
}

This report documents initial work for an ongoing research effort by the U.S. Army Research Institute for the Behavioral and Social Sciences (ARI) ${ }^{1}$ titled Battle Command Visualization 101. The research focuses on providing a prototype example of embedded training for individuals in company-level command groups employing networked sensors in the Future Force. Because the visualization skills targeted by this research are basic or " 101 " introductory level skills for battle command visualization (BCV), the training program is referred to as BCV 101. Based on the research reported here, a follow-on BCV 101 research effort is underway and will be documented in a subsequent report.

\section{Organization of the Report}

The Background section of this report discusses the major research and development underpinnings for the work. The Research Method section then addresses three primary research areas: design of an embedded training program for employing networked sensors, design of a subset of training exercises for the program, and development of 20 exercises in a prototype command and control $\left(\mathrm{C}^{2}\right)$ system. The final sections of the report address training implications for follow-on BCV 101 research, and potentially for embedded training development.

\section{Background}

The BCV 101 training program stems from the operational expectations for Soldiers equipped with Future Combat Systems (FCS) in the U.S. Army's Future Force. The Army's ongoing transformation to FCS poses an unprecedented alliance of humans and machines. Currently, FCS is essentially a conceptual design featuring an interdependent system-of-systems (Department of the Army [DA], 2003b). Interdependence is reflected in the concept of a network-centric force composed of modular manned and progressively autonomous platforms with networked communication, sensor, and fire capabilities.

The Future Force equipped with FCS will be more strategically employable, with the requirement for rapid deployment and seamless operations across the full spectrum of military operations. The Army has identified four Qualities of Firsts that the Future Force must possess to operate effectively in that future environment: See First, Understand First, Act First, and Finish Decisively. Training that supports these Qualities must be embedded in every Future Force operational system, and in supporting systems, including laptop computers and personal digital assistants (DA, 2003b).

The BCV 101 training program is focused on sensor exploitation to support the See First Quality. This Background section describes what that Quality means, how training and system developments are evolving to support the Quality, and what initial research efforts are revealing about skills and skill acquisition for See First.

\footnotetext{
${ }^{1}$ Appendix A contains a list of all acronyms used in this report.
} 


\section{The Quality of "See First"}

The Qualities of Firsts are critical for transformation to the Future Force. To promote transformation, these Qualities are already appearing in the latest generation of U.S. Army manuals. By relating familiar processes to the Qualities, the doctrinal discussions give direction and definition to superior information awareness. The Army's Field Manual (FM) 6-0, Mission Command (DA, 2003a), states that the See First Quality "... equates to the 'observe' activity but emphasizes accomplishing it before the enemy does" (p. A-3). The See First Quality is related directly to familiar reconnaissance and force protection concepts in that it emphasizes the processes of discovering information about the enemy and shielding friendly information from the enemy while developing the situation out of contact.

The ability to integrate the raw data flowing into the $\mathrm{C}^{2}$ system with already-processed information to construct a coherent common operating picture has long been a critical requirement for commanders. For the Future Force, the commander is still the critical link, but commanders at all levels down to the company will have greater access to all collection sources on the battlefield. As commanders enter Future Force organizational structures, they will adapt familiar methods and procedures to exploit the new capabilities. The start-point of the operational planning-execution cycle for Future Forces is described in FM 6-0 (DA, 2003a) in this way:

During operations, commanders first observe the situation - that is, they collect information. They learn about the status of their own forces, the environment, and the enemy through intelligence, surveillance, reconnaissance, information systems (INFOSYS), and reports from other headquarters. Sometimes they actively seek information; sometimes the command and control $\left(\mathrm{C}^{2}\right)$ system disseminates it to them (p. A-1).

The U.S. Army Training and Doctrine Command (TRADOC) pamphlet Military Operations, Objective Force Maneuver Units of Action (DA, 2002) also discusses the Quality of See First for Future Forces. Future Force units, using the networked, cooperative sensors within the joint operational environment, will see the enemy as a whole complex and adaptive organization. Commanders will have the ability to examine and follow up on any particular input into the system for their own purposes in order to gain key and critical information affecting an immediate decision. Parallel analyses will be conducted by higher, lower, adjacent, and supporting commanders working to identify critical enemy decisions or actions that indicate a particular enemy course of action. The data and conclusions will be mutually informing and supporting, allowing for a rich and accurate common operational picture that assists commanders in understanding what the enemy is currently doing, and what he may do next.

\section{Training for See First}

Soldiers face formidable tasks at every level to provide relevant contributions to the requirements of the See First Quality. One assumption under the See First Quality requires that every Soldier, not just sensor operators, understand the capabilities and limitations of the sensor network (ARI, 2003). This basic understanding will enable the use of the sensor network to gain 
a common operating picture within the unit effectively and efficiently. The requisite technical and tactical skills of the Future Force command group will have to reside at every echelon, allowing full and immediate exploitation of every advantage on the battlefield. Commanders will force cross training in critical skills across the command group in order to exploit technological strengths and shield technological limitations.

The assumption that only technical experts will examine and process raw data from the sensor network is untenable in the time-constrained future battlefield. A more viable assumption is that multi-skilled warfighters, including small unit command groups, will need to gather and analyze disparate sensor data into information, into a coherent and immediately comprehensible operational picture. The challenge is exacerbated by the fact that every combat organization in the Future Force will have organic sensors, including unmanned air vehicles (UAVs), from platoon level up. The lower echelons of command do not have staff or trained intelligence specialists to help analyze the information.

Early prototyping for testing key concepts - such as networked sensor employment and embedded training - provides a method of shortening the cycle from concept, to development, to operational asset. Early prototyping, however, should not be limited to work on the operational use of technologies; parallel efforts should be ongoing for training as well. By introducing visualization ${ }^{2}$ training along with the operational system itself, developers ensure that the Future Force Soldier will be able to learn to use the operational system to its fullest advantage. This binding of operations and training offers more immediately a proficient starting performance for Soldiers as soon as the systems are fielded. Additionally, the embedded training paradigm (Gossman, Flynn, \& Breidenbach, 2004) posits that training systems will accompany Soldiers during the training-alert-strategic movement-operations cycle of deployment. This capability will increase the ability of the unit to achieve a high level of mission-specific proficiency. Training that capitalizes on the ability of the Future Force to receive direct sensor feeds at any point before and during deployment will help commanders See First.

Training on networked sensors sooner rather than later will help Soldiers adapt from current to future methods for observing the battlefield. With an advanced array of individual networked sensors capable of cross cueing (passing information and commands to each other and acting together to gather additional information), the Future Force will see the enemy in realtime. Exploitation of the robust and numerous echeloned sensor systems from tactical to strategic levels will be enabled by human-computer capabilities to quickly categorize, store, and broadcast the data as useful information.

\section{Sensors in Support of See First}

The Future Force will gain information through a system of networked sensors. The use of air sensor platforms, particularly unmanned platforms, represents a significant departure from

\footnotetext{
${ }^{2}$ In common language, "visualization" is "...the act or power of forming visual images of objects not present to the eye" (G. \& C. Merriam Company, 1961). When used in the context of battle command, it takes on greater meaning, as the core mental process that commanders use in decision-making to determine how to get forces from their current state or position to the end state that represents mission accomplishment (DA, 2003a). The first step in the visualization process is to collect information, hence the "101" in BCV 101.
} 
the Current Force operation that is vital to the Quality of See First. Unmanned systems will increasingly provide small unit commanders with reports, snapshots, and live video outputs of battlefield conditions. Pushing sensors and their capabilities downward to the platoon level represents a key shift in decision-making and operation.

The sensor capabilities that enable Future Force units to receive continual feeds of critical data include (a) rapid movement around the battlefield, (b) comparatively long standoff while observing due to altitude and sensing systems, (c) survivability through size and speed, and (d) communication of real-time images across networks. Once trained, Soldiers will be able to use the sensor networks to detect above surface, surface, and subsurface targets through electrooptical, thermal, acoustic, magnetic, chemical, and seismic activity. Sensors will be equipped with both passive and active systems to provide target acquisition, real-time tracking, and identification of entities in the area of operations for the unit. Sensor data and other information form the basis of commander's ability to See First, make decisions, and control manned and robotic units on the battlefield.

Some, but not all, of the Army's thinking and planning for UAV sensors is based on real systems currently being used, some of which are shown in Figure 1. Certain systems, including the Hunter and Shadow 200 UAVs, have received intensive workouts during Operation Iraqi Freedom (Odierno, 2004).
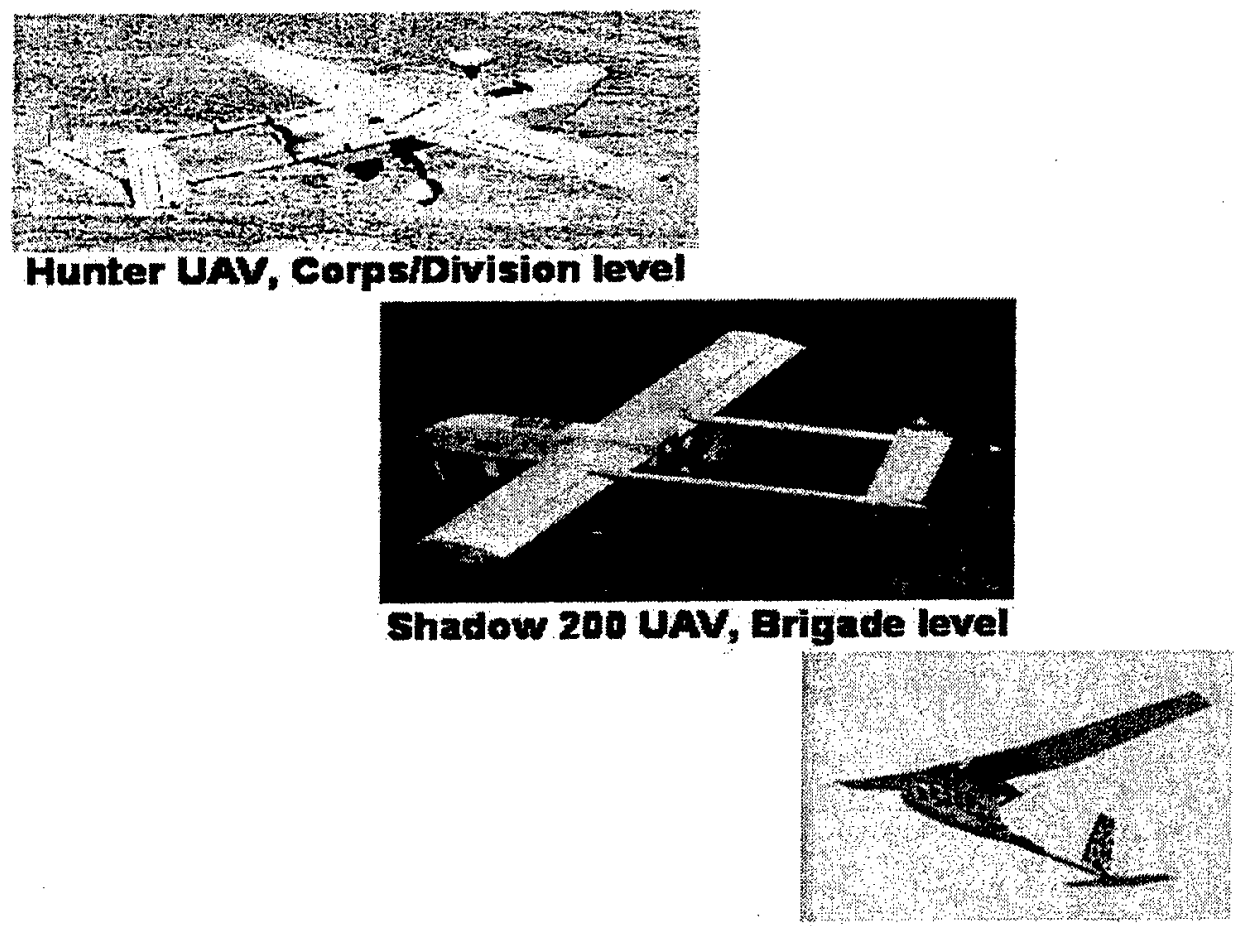

Raven UAV, En a below level

Figure 1. Sample of current operational unmanned air vehicles (UAVs).

At the center of Figure 1, the Shadow 200 is a brigade-level UAV equipped with an electro-optical/infrared (EO/IR) sensor turret. The use of EO/IR technology enables transmission of real-time video in both daylight (visible) and obscured (thermal) conditions. At 
11 feet long with a 13-foot wingspan, the Shadow 200 can cruise at 70 knots for up to 6 hours at an altitude of 14,000 feet. The larger "Hunter" is a division-corps UAV and has increased operating characteristics in terms of speed, altitude, and flight time. At the other end of the spectrum, small hand-launched UAVs such as the "Raven" are also being used in Iraq and in Afghanistan (Operation Enduring Freedom). The Raven weighs in at about 6 pounds and has a 4-1/2 foot wingspan. It carries a 2-pound EO/IR camera, and can fly for 60 to 80 minutes out to a range of about 10 kilometers. In theory, the Raven would be used at the discretion of the tactical or small unit commander without the need for permission from brigade or higher echelons.

Other UAVs are under development at the Defense Advanced Research Projects Agency (DARPA), such as the A160 Hummingbird rotorcraft. The A160 UAV uses a hinge-less, rigid rotor to achieve a high-endurance (over 24 hours), high-altitude (30,000 feet) capability. With its synthetic aperture radar (SAR), snapshots can be transmitted back to the unit, and moving target indicator (MTI) technology supports detection and reporting of movement in the area. Designs for microUAVs, which are miniature aircraft, less than 6 inches in any dimension, are being explored by DARPA. The DARPA microUAVs are designed to aid individual Soldiers and Marines fighting in urban areas and close terrain. The program is pushing technologies such as small, lightweight propulsion, small sensors, and communication technologies (Tiron, 2001).

Thus, there is still a great deal of conceptualizing, developing, and decision-making to be done in the area of UAV planning, design, and procurement. Proactive research and development efforts such as those described below often portray system capabilities that do not yet exist - to advance experimentation on human performance, to explore and refine operational concepts, and to develop prototype training methods.

\section{Preliminary Research with Sensors and See First Training}

The U.S. Army's Communications-Electronics Command (CECOM) at Fort Monmouth worked with DARPA on the FCS C ${ }^{2}$ research program to conduct a series of exploratory experiments with Future Force organizations and equipment (Lickteig, Sanders, Durlach, Lussier, \& Carnahan, 2003). The virtual simulation for this work represented a Future Force environment for a notional FCS small unit under a company-level command group.

Training requirements for a small command group with highly automated and interdependent network-based systems may entail unprecedented levels of tactical and technical expertise (Lickteig et al., 2003). For new participants in the FCS C ${ }^{2}$ program, introductory training and practice required two weeks followed by a one-week experimentation period. In the main, this introductory training began with a lecture-based non-interactive slide show primer to show concepts and graphic depictions of weapon and sensor systems, including individual sensor coverage and outcomes. Depictions of this type showing idealized results offer excellent information, but little opportunity for participants to assimilate the skills and interactions associated with the range of networked, organic, and external sensors required for their missions.

Providing information is not necessarily a bad approach to training, but it is usually incomplete; the training ought not to stop there. Observations of the FCS C ${ }^{2}$ training suggested 
that the $\mathrm{C}^{2}$ interface could be adapted to introduce, familiarize, and train proficiency with multiple aspects of sensor employment and exploitation. Once Soldiers were trained on use of the $\mathrm{C}^{2}$ interface itself and had practiced with overlays, files, and various menu-driven features, they would be able to engage in high-fidelity interactive multimedia training using the system features. Whether or not the interface could in fact be adapted was unknown, but the notion of using a simulated operational $\mathrm{C}^{2}$ system to support training on that system closely parallels expectations for Future Force embedded training (DA, 2003b; Throne \& Burnside, 2002).

Lessons learned from the FCS $\mathrm{C}^{2}$ experiments centered on the difficulties that even experienced participants had in mastering the technical and tactical aspects of individual and networked sensors. For example, participants were frequently unable to recognize and identify individual elements in the enemy array. This array included a large number of vehicle types along with dismounted Infantry Soldiers. Even when the participants could conduct the basics of See First initially, they soon became overwhelmed by the mass of data from the sensors. They sometimes lost track of individual threat entities and were unable to assemble and visualize an accurate common operating picture. Similar shortcomings in battlefield visualization and associated skills were identified previously, particularly at the commander and staff levels (Reilly, 1997; Solick, Spiegel, Lussier, \& Keene, 1997). Effective training in basic visualization skills is needed now more than before to meet the See First objective.

\section{Research Requirement}

Realization of the increased demands that the future operating environment will place on Soldiers, coupled with understanding of the performance shortcomings already identified in current environments, led to the research requirement on which this project was based.

Specifically, research was needed that would result in a prototype design for embedded training (DA, 2003b) with a focus on employing networked sensors.

For the initial BCV 101 effort, the design would specify a set of exercises to provide a graduated approach to skill acquisition and include a representative sample of simulation-based exercises developed on a prototype $C^{2}$ system. Assessment of the exercises for the initial effort was limited to pilot tryouts and demonstrations for formative evaluation, with more rigorous external evaluations anticipated in follow-on efforts. A more immediate goal of the BCV 101 effort was to support participant training for future experiments by the FCS $\mathrm{C}^{2}$ research program, currently called the Multi-Cell and Dismounted Command and Control (M\&D C ${ }^{2}$ ) research program. A more extended goal was to develop a working example of embedded training on sensor exploitation required by FCS and the Future Force.

\section{Research Method}

The research methods for BCV 101 comprised three distinct but related areas. "Training Program Design" examines the basic design parameters and training requirements and then describes the training program designed to address those requirements. "Exercise Design" describes a representative subset of 20 exercises prepared to convey an understanding of the capabilities and limitations of networked sensors. "Exercise Development" documents the process and results of an attempt to develop the 20 exercises on a futuristic $\mathrm{C}^{2}$ system. 


\section{Training Program Design}

The BCV 101 training concept for basic visualization skills acquisition includes several key design parameters (ARI, 2003). Overall, the training should comprise a large set of relatively short exercises (5-10 minutes), giving individual participants multiple practice and feedback opportunities to facilitate skill acquisition and reinforcement (Sanders, 2003; West, Farmer, \& Wolff, 1991). Together, the set of exercises should systematically vary the range of task and/or battlefield conditions under which networked sensors would be used and convey the capabilities and limitations of individual and networked sensors for small unit command groups.

The training should vary task conditions in a progressive and systematic fashion to provide skill reinforcement while simultaneously increasing performance difficulty. The prescribed progression through the exercises should be computer-assisted, so that each participant's progress would be optimal in terms of performance difficulty and skill reinforcement.

A series of gates (criterion performance tests) should be presented at strategic locations or times in the progression, both to ensure that training participants would demonstrate lower level skills prior to beginning work on more difficult skills, and also to permit fast learners to proceed through the exercises efficiently. Gated performance also provides the data required to manage training in embedded and related training delivery systems referred to as learning management systems (Appendix B, p. B-5). Computer-assisted training should also reduce the demand for expert trainers, and allow progression and feedback to be standardized.

Training in BCV 101 should concentrate primarily on the conceptual skills required to exploit sensors rather than procedural skills or "switchology" required simply to control sensor activity. The specific sensor systems for this initial training design were limited to UAVmounted sensors, and included electro-optical and thermal video, SAR, and MTI radar. The design is scalable, however, allowing later expansion to include additional sensor systems or network capabilities.

In effect, the design parameters are similar to the familiar and successful Conduct-of-Fire Trainer (COFT) model (COFT, 2003). Like COFT, the plan was to have exercises of graduated difficulty and short duration, structured and ordered to concentrate on specific sensors and their outputs. Figure 2 illustrates the broad concept for systematic variations in task conditions that would enable progressive difficulty.

In Figure 2, the variations in task conditions that will define the training matrix include considerations of sensor type, weather/visibility, terrain types, enemy/target status (including type, number, activity, and countermeasures such as cover and concealment), and cue type detection or prediction. 


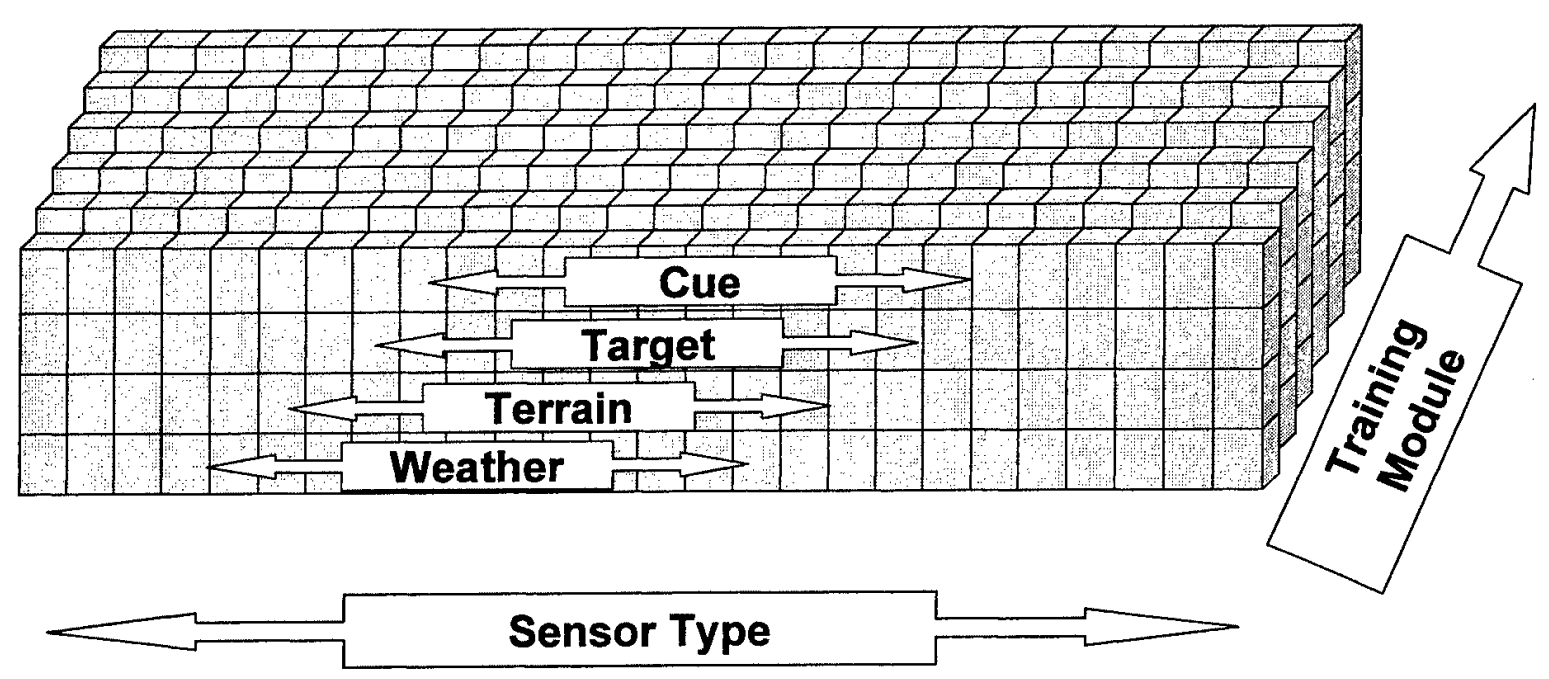

Figure 2. Systematic variations in task conditions for training exercise matrix.

Figure 3 provides a more detailed example that shows a progressive matrix model that varies type and number of sensors, visibility (day, night), and a small representative selection of targets. If all task conditions and combinations of conditions for the variables shown in the matrix in Figure 2 were developed into exercises, there would be upwards of 1500 exercises. The array shown in Figure 3 represents a systematic sample of the domain of conditions preserving the progressive difficulty feature while avoiding an exhaustive (and exhausting, and unnecessary) inclusion of all possible exercises.

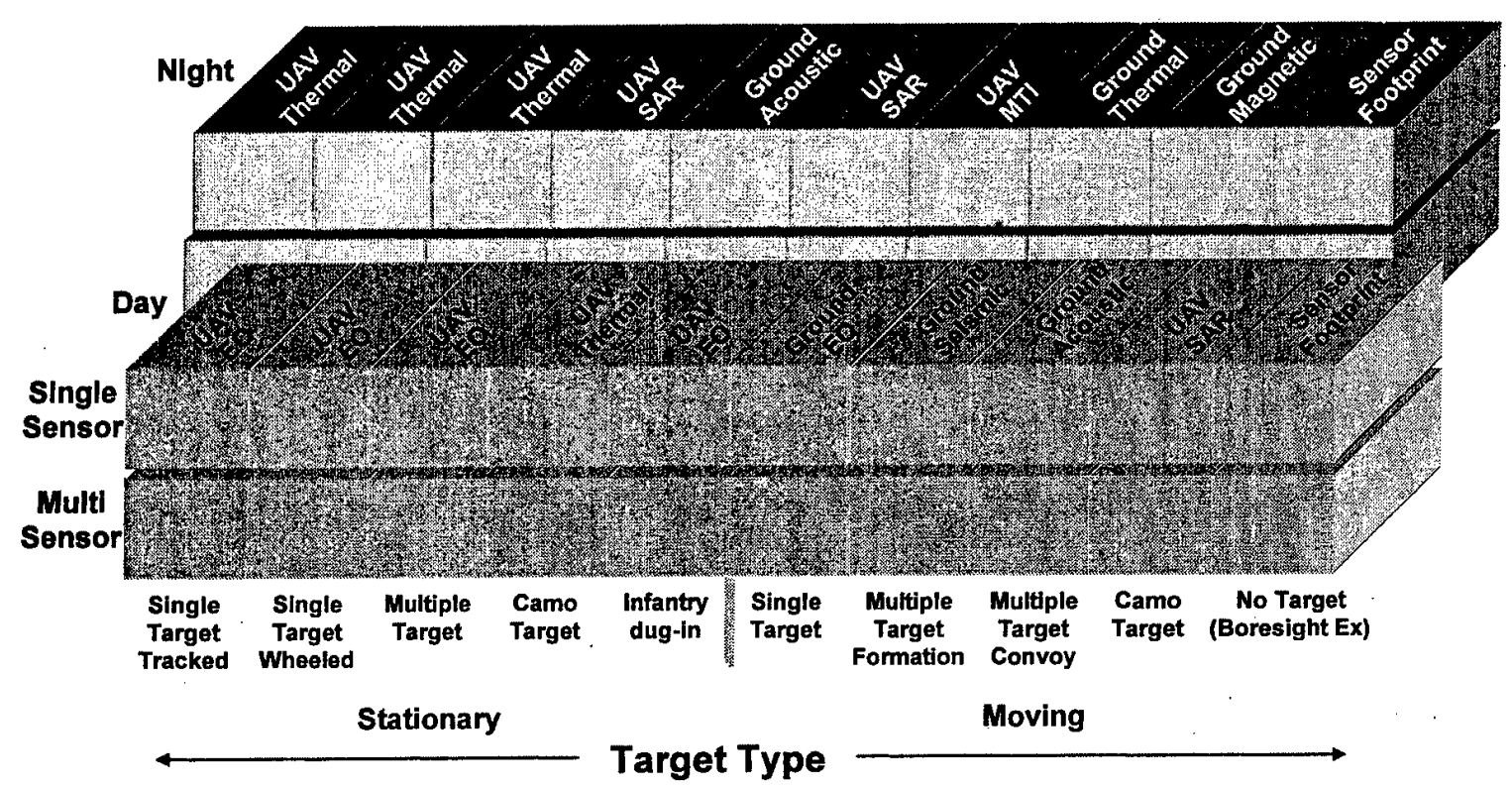

Figure 3. Initial sensor training progression matrix.

The resulting BCV 101 training program design is documented in Appendix B. The design provides a general framework for exercise design and development and addresses each of the key design parameters previously discussed. Notably, the design is organized into four modules that reflect an individual training sequence based on performance difficulty and 
progression from enabling skill to terminal skill, as described in Appendix B. The four training modules demonstrate the building block approach concerning sensor capabilities and limitations for a See First training objective. Table 1 summarizes the purpose and approach for each of the four training module.

\section{Table 1}

Overview of Purpose and Approach for Four Modules in the Training Design for BCV 101

Module 1:
Sensor
Capabilities,
Limitations,
and
Vulnerabilitie

Purpose: To train the participants on their unit's organic sensor capabilities, limitations, and vulnerabilities, as well as the external sensors that may be made available to them. Participants will also be trained on the methods that enemy forces can be expected to use to destroy sensors, spoof them, or negate their capabilities.

Approach: Participants will be shown a series of informational pages, pictures, animations, and simulations that will cover the capabilities, limitations, and vulnerabilities for each system. Where appropriate they will be provided tactics, techniques, and procedures (TTPs) on the employment of various systems. Specific information covered during this training will include the effects of weather and terrain on the sensor.

Participants will be presented tactical situations with various weather, terrain, and enemy conditions and asked to select the appropriate sensor. The participant could also be asked to identify raw sensor images and determine which sensor provided the image. The participant could also be provided degraded sensor images and be asked to identify changes to the sensor payload or mission tasking (such as altitude, speed, sensor payload orientation) that could improve the quality of the image.

Module 2:
Sensor Tasking

Purpose: To train participants to task organic unit sensors to gain information to answer the commander's critical information requirements (CCIR) and Priority Intelligence Requests (PIR). The participants will also be trained to identify CCIR and PIR that are beyond the capabilities of their unit's organic capabilities and to initiate requests for information to higher headquarters to obtain support from external sensors to provide the needed support.

Approach: Participants will be provided a tactical framework, including the higher unit's reconnaissance and surveillance (R\&S) plan and overlay, CCIRs and PIRs and intelligence summaries. A visual projection of the location of all friendly forces based on the common operational picture will be available. They will also be provided their unit's R\&S tasking matrix that has been completed except for the designation of the sensor that will be employed to answer the CCIR/PIR. The matrix is designed so that each successive task becomes more complex through manipulation of weather, terrain, the target type, the availability of sensors, and the ambiguity of the enemy situation.

To answer each PIR, the participant will be required to select from a list of possible sensor taskings that provide the sensor's mission profile (speed, altitude, sensor payload, sensor payload orientation, and other pertinent information). Once the participant selects a sensor, the interactive courseware will provide a simulation of the sensor tasking and provide the appropriate sensor output for that selection. If the participant has made the adequate selection, the desired information will be displayed. If the participant has made an inadequate selection, the participant will be provided additional feedback as to why that selection was incorrect and then be required to make another selection. This process will be repeated until all of the pre-designated PIR elements have been covered.

Initially, the participant will be selecting taskings for individual sensors. Later in the module, the participant will be required to select among multiple combinations of sensors to answer the CCIR/PIR. As the participant progresses through the training, the amount of feedback or coaching that is being presented for an incorrect selection will be reduced so that by the end of the training level the participants have to determine where they made an error without outside assistance. 


$\begin{array}{ll}\text { Module 3: } & \text { Purpose: To train the participants to dynamically retask organic unit or external higher- } \\ \text { Dynamic Sensor } & \text { headquarters sensors based on changing mission, enemy, troops, terrain, time, and civilian } \\ \text { Retasking } & \text { considerations (METT-TC) factors. }\end{array}$

Approach: Participants dynamically retask sensors during a series of increasingly complex exercises in which there is a dynamic friendly and enemy situation. Their sensor retasking will be expected to answer time-sensitive CCIR/PIRs. The participant is provided the higher unit's intelligence, surveillance, and reconnaissance plan and overlay, CCIRs and PIRs, and intelligence summaries. The location of all friendly and detected enemy forces will be displayed on a visual projection of the common operational picture. Initially, the participant will be executing an R\&S tasking matrix in which the sensor tasking has already been developed. During the course of task execution, the participant will be provided additional information, which will cause the participant to change the sensor tasking.

As the participant progresses through the levels, the number of sensors that the participant will have to retask and the potential vulnerability of the sensors to enemy action will increase. Simultaneously, decreases will occur in the amount of information provided about the enemy, and the amount of time between the retasking directive from the participant's commander until the enemy situational information is expected to be presented.

Module 4: Sensor Integration into Tactical Operations
Purpose: To train the participants to integrate organic unit-level sensors and available higher headquarters sensors into Intelligence, Surveillance, and Reconnaissance (ISR) operations.

Approach: The participants plan and execute a series of ISR operations, primarily focused on organic unit-level sensors and available higher headquarters sensor support. They will develop an ISR plan that includes an R\&S tasking matrix and an R\&S overlay to gain information to support the CCIR/PIR. The participants will then execute the ISR plan, making adjustments to sensor taskings based on an evolving enemy and friendly situation. Participant performance will be graded based on the amount of information that is obtained from the ISR plan and the efficiency of the operation in terms of whether the sensor tasking obtained the desired information (more information is better), number of sensors required to obtain the information (fewer is better), the number of sensor losses due to enemy activity (fewer is better), and the amount of time required to answer the CCIR/PIR (shorter is better). As the participant progresses through the training, the ISR tasks become increasingly complex based on the tactical situation. For example, the initial operation might be an attack against a defending enemy located in open terrain. Subsequent operations may include moving enemy forces, complex terrain such as jungles or forests, and urban operations. The embedded Learning Management System (LMS) will track participant performance. If the performance warrants, the student will be referred back to Module 2 or 3 for refresher training. At the successful completion of the training, the participant's training record will be annotated by the LMS and an appropriate training certificate issued.

Within the design description are initial recommendations on training audience, prerequisite training, and training objectives. Entering as an untrained participant, the individual will perform a series of tasks to acquire a basic understanding of sensor concepts and idealized outputs, and then conduct controlled and directed practice exercises to build upon this base. Certain exercises function as criterion checks on learning, or gate exercises, to verify knowledge of basic sensor capabilities and outputs.

The BCV 101 design is predicated on a small set of specified training prerequisites. Particularly, the expectation is that participants are already trained on general operation of the $\mathrm{C}^{2}$ system in which the training program will be embedded. They should also be familiar with their unit's organization and equipment, including the types and numbers of organic sensor systems; the types, numbers, and capabilities of external sensors that may be made available to them; and, 
troop leading procedures at the company or troop level, which includes reconnaissance and surveillance planning.

With these stipulations on prerequisite skills, the training design could concentrate on tasks more directly related to the See First Quality. Target recognition tasks would also be trained separately, though BCV 101 would reinforce this pre-training through the exercises. The exact nature of the prerequisite tasks for BCV 101 was not delineated; that information would best be determined as a byproduct of prototype experiments with the training.

Critical to understanding the training design for BCV 101 are the embedded training requirements that initiated and guided the research effort (DA, 2003b). The FCS embedded training requirement is that the participant can conduct training on an actual operational system. For the target training audience, an FCS company command group, the requirement is for training available in their $\mathrm{C}^{2}$ vehicle and delivered via their $\mathrm{C}^{2}$ system. Embedded training should also provide high-fidelity and performance-based training. For high fidelity, the training mode of BCV 101 should look and perform like a $\mathrm{C}^{2}$ system in the operational mode. Training should also provide a performance medium, namely virtual simulation, which accurately models the interactive conditions, behaviors, and outcomes associated with networked sensors.

\section{Exercise Design}

Based on the BCV 101 training framework in Appendix B, a sample of 20 exercises on networked sensors were designed and developed in a COFT-like training matrix. Design focused on conceptual skills, in part because the exact configuration of future $\mathrm{C}^{2}$ systems and FCS sensor networks are still evolving. Design also addressed a limited set of procedural skills to employ sensors, but basic procedural operations were identified as a prerequisite for BCV 101 training.

The sample exercises were designed to address technical and tactical aspects of sensor exploitation. To train conceptual skills, the exercises required more than passive viewing of sensor outputs under different conditions, but did not require participants to procedurally select sensor systems, input sensor routes, or flight patterns, or designate a search area. Rather, the primary task for the participant was recognition and identification of the sensor images received during the exercise. A secondary task was to relate the sensor information received to the commander's information requirements and the tactical setting.

Three key design decisions affected the purpose and approach for the sample set of exercises. First, the exercises were constrained to three air sensor systems for the initial BCV 101 effort to limit development to a manageable segment of the domain. These were two UAVs, the Shadow 200, and A160 Hummingbirds with SAR or MTI radar sensors, and four microUAVs that provided camera-based sensor images. Second, sensor capabilities and limitations were based on the sensor models incorporated in the $C^{2}$ system developed by DARPA and CECOM. Finally, the exercises were set in a digital terrain database of the National Training Center (NTC) at Fort Irwin, CA, that was used by the FCS C ${ }^{2}$ program.

In terms of covering the complete domain of sensors, terrain, and participant activity, these design decisions may seem severely constraining. However, in terms of demonstrating the 
BCV 101 training approach, there was less need to represent the complete domain, and a greater need to take advantage of available resources for this initial exercise development effort. Table 2 contains basic descriptions of the 20 exercises developed during the current effort. The followon BCV 101 effort will expand the training to approximately 90 exercises and relate them to a Sensor Training Matrix that is only notionally depicted in Figures 2 and 3.

Table 2

Basic Specifications for 20 Exercises in the Sensor Training Matrix

\begin{tabular}{|c|c|c|c|}
\hline Exercise & Task & $\begin{array}{l}\text { Unmanned Air Vehicle } \\
\text { System(s) }\end{array}$ & Target Type and Condition \\
\hline 1 & Confirm cooperative cueing and outputs & Shadow 200 , microUAV & 1 Stationary Draega \\
\hline 2 & Confirm cooperative cueing and outputs & Shadow 200 , microUAV & 1 Stationary GARM \\
\hline 3 & Confirm cooperative cueing and outputs & Shadow 200, microUAV & 1 Stationary BRDM-AT \\
\hline 4 & $\begin{array}{l}\text { Identify and report, confirming SAR } \\
\text { detections }\end{array}$ & Shadow 200 , microUAV & 1 Stationary Draega \\
\hline 5 & $\begin{array}{l}\text { Identify and report, confirming SAR } \\
\text { detections }\end{array}$ & Shadow 200, microUAV & 1 Stationary BRDM \\
\hline 6 & $\begin{array}{l}\text { Identify and report, confirming SAR } \\
\text { detections }\end{array}$ & Shadow 200, microUAV & 1 Stationary Draega \\
\hline 7 & $\begin{array}{l}\text { Identify and report, confirming SAR } \\
\text { detections }\end{array}$ & Shadow 200, microUAV & Stationary 1 Draega, 1 GARM, 1 Darya \\
\hline 8 & Confirm templated enemy assembly area & Shadow 200 , microUAV & Stationary Draegas, GARMs, Ural trucks \\
\hline 9 & $\begin{array}{l}\text { Detect and confirm intelligence report of } \\
\text { an enemy formation }\end{array}$ & $\begin{array}{l}\text { A160 (MTI), Shadow } \\
200, \text { microUAV }\end{array}$ & Moving Draegas, GARM \\
\hline 10 & $\begin{array}{l}\text { Detect and confirm intelligence report of } \\
\text { an enemy column }\end{array}$ & $\begin{array}{l}\text { A160 (MTI), Shadow } \\
200, \text { microUAV }\end{array}$ & Moving Draegas, GARMs, BRDMs \\
\hline 11 & Detect and confirm intelligence report & Shadow 200 , microUAV & 1 Stationary, dug-in or camouflaged Purga \\
\hline 12 & Confirm templated enemy positions & $\begin{array}{l}\text { A160 (SAR), Shadow } \\
200, \text { microUAV }\end{array}$ & $\begin{array}{l}\text { Stationary, dug-in or camouflaged } 2 \\
\text { Draegas, } 2 \text { GARMs, } 2 \text { Purgas; } \\
\text { Civilian vehicles present }\end{array}$ \\
\hline 13 & $\begin{array}{l}\text { Confirm intelligence reports and } \\
\text { templated enemy positions }\end{array}$ & $\begin{array}{l}\text { A160 (SAR), Shadow } \\
200 \text {, microUAV }\end{array}$ & $\begin{array}{l}\text { Stationary, dug-in or camouflaged } 3 \\
\text { GARMs, } 2 \text { BRDM-ATs, } 4 \text { dismounted } \\
\text { infantry squads; Civilian vehicles present }\end{array}$ \\
\hline 14 & $\begin{array}{l}\text { Confirm intelligence report of company- } \\
\text { size Assembly Area }\end{array}$ & Shadow 200, microUAV & $\begin{array}{l}3 \text { Stationary Draegas, } 3 \text { GARMs, } 2 \text { Ural } \\
\text { trucks; Civilian vehicles present }\end{array}$ \\
\hline 15 & $\begin{array}{l}\text { Confirm intelligence report of a moving } \\
\text { company sized unit }\end{array}$ & Shadow 200, microUAV & $\begin{array}{l}6 \text { Moving Garms, } 3 \text { BRDM-ATs; Civilian } \\
\text { vehicles present }\end{array}$ \\
\hline 16 & $\begin{array}{l}\text { Confirm template position of artillery unit } \\
\text { in firing position }\end{array}$ & Shadow 200 , microUAV & $\begin{array}{l}\text { Stationary, in firing position, } 5 \text { Purgas, } 5 \\
\text { Ural trucks }\end{array}$ \\
\hline 17 & $\begin{array}{l}\text { Confirm intelligence report of tactically } \\
\text { moving mixed formation }\end{array}$ & Shadow 200 , microUAV & 1 Moving Draega, 2 GARMs, 3 BRDMs \\
\hline
\end{tabular}




\begin{tabular}{|c|c|c|c|}
\hline Exercise & Task & $\begin{array}{l}\text { Unmanned Air Vehicle } \\
\text { System(s) }\end{array}$ & Target Type and Condition \\
\hline 18 & $\begin{array}{l}\text { Confirm intelligence report of a tactically } \\
\text { moving formation }\end{array}$ & Shadow 200, microUAV & $\begin{array}{l}3 \text { Moving BRDM-Recons, } 3 \text { Orels; Civilian } \\
\text { vehicles present }\end{array}$ \\
\hline 19 & $\begin{array}{l}\text { Detect, identify and confirm multiple } \\
\text { inteligence reports of stationary and } \\
\text { moving enemy formations }\end{array}$ & $\begin{array}{l}\text { A160 (MTI), A160 (SAR), } \\
\text { Shadow 200, } 3 \\
\text { microUAVs }\end{array}$ & $\begin{array}{l}3 \text { Draegas, } 3 \text { GARMs, } 1 \text { Purga, } 1 \text { Darya, } 1 \\
\text { BRDM-Recon, } 1 \text { BRDM-AT, } 3 \text { Ural trucks, } \\
3 \text { MTLBs }\end{array}$ \\
\hline 20 & $\begin{array}{l}\text { Detect, identify and confirm multiple } \\
\text { intelligence reports of stationary and } \\
\text { moving enemy formations }\end{array}$ & $\begin{array}{l}\text { A160 (MTI), A160 (SAR), } \\
\text { Shadow 200, } 3 \\
\text { microUAVs }\end{array}$ & $\begin{array}{l}3 \text { Draegas, } 2 \text { GARMs, } 1 \text { Purga, } 1 \text { SA-13, } 2 \\
\text { Daryas, } 3 \text { BRDM-Recons, } 1 \text { Ural truck }\end{array}$ \\
\hline
\end{tabular}

Note: Under "Target Type and Condition", the named systems are all former Soviet/Warsaw Pact style vehicles or platforms and developments of them - BRDM-variants, Draegas (tanks), Daryas (artillery), GARMs (IFVs), MTLBs, Purgas, SA-13s, Orels, and Ural trucks. "microUAV" = micro unmanned air vehicle. "A160" = Hummingbird unmanned air vehicle. "SAR" = synthetic aperture radar. "MTI" = moving target indicator.

The training matrix in Table 2 begins with single stationary targets and progresses to situations with multiple moving targets. Participants are first faced with a basic series of short tasks to determine what is at the forward edge of the battle area and in near contact with friendly forces. Subsequent exercises require the participants to observe the battle area in depth including multiple moving targets. All target type conditions are set to require participants to recognize and identify potential threats on the battlefield. Overall, the matrix represents a COFT-like progressive system of increasing difficulty and complexity in structured, repeatable training.

The specifications in Table 2 contain information on three key sensor related parameters: task, sensor system(s), and target type/condition. Additional parameters, including named areas of interest and enemy locations (grid coordinates) are specified in Appendix C. As might be expected, the sensor characteristics available in the prototype $C^{2}$ system were also key in the design of the sample exercises. In contrast, the available terrain database from the NTC was not. A developer could situate similar exercises in the mountains of Afghanistan, built-up areas in central Europe, or jungles in Southeast Asia. Design adaptations to other terrain should occur, as other digital terrain databases are available for future efforts.

\section{Exercise Development}

Exercise development used a prototype $\mathrm{C}^{2}$ system developed by the FCS $\mathrm{C}^{2}$ program for exploring FCS command and control issues. Notably, the FCS C ${ }^{2}$ system used for BCV 101 is not the actual $\mathrm{C}^{2}$ system currently under development for FCS. However, the FCS $\mathrm{C}^{2}$ prototype represents DARPA's unique and leading-edge approach to the command and control of manned and robotic/unmanned elements for FCS. The FCS $\mathrm{C}^{2}$ prototype system, referred to hereafter as the $\mathrm{C}^{2}$ system, reflects the commander-centric and networked sensor focus required for the Future Force to See First. Coupled with virtual simulation models, the $\mathrm{C}^{2}$ system represents the FCS interdependent system-of-systems concept and a high fidelity environment for developing embedded training on networked sensors.

Figure 4 provides an overview illustration of the $C^{2}$ system in a surrogate $C^{2}$ vehicle, as configured for the FCS $\mathrm{C}^{2}$ program. The four participant command group members in the foreground are identically equipped with a dual monitor interface to the $\mathrm{C}^{2}$ system. The $\mathrm{C}^{2}$ 
system at Fort Monmouth for the FCS $\mathrm{C}^{2}$ program comprised over 20 separate computer servers operating in a network to support the command group. For BCV 101 training development, a scaled-down version of the $\mathrm{C}^{2}$ system, with 12 servers and one dual monitor interface, was developed by CECOM and provided to ARI at Fort Knox.

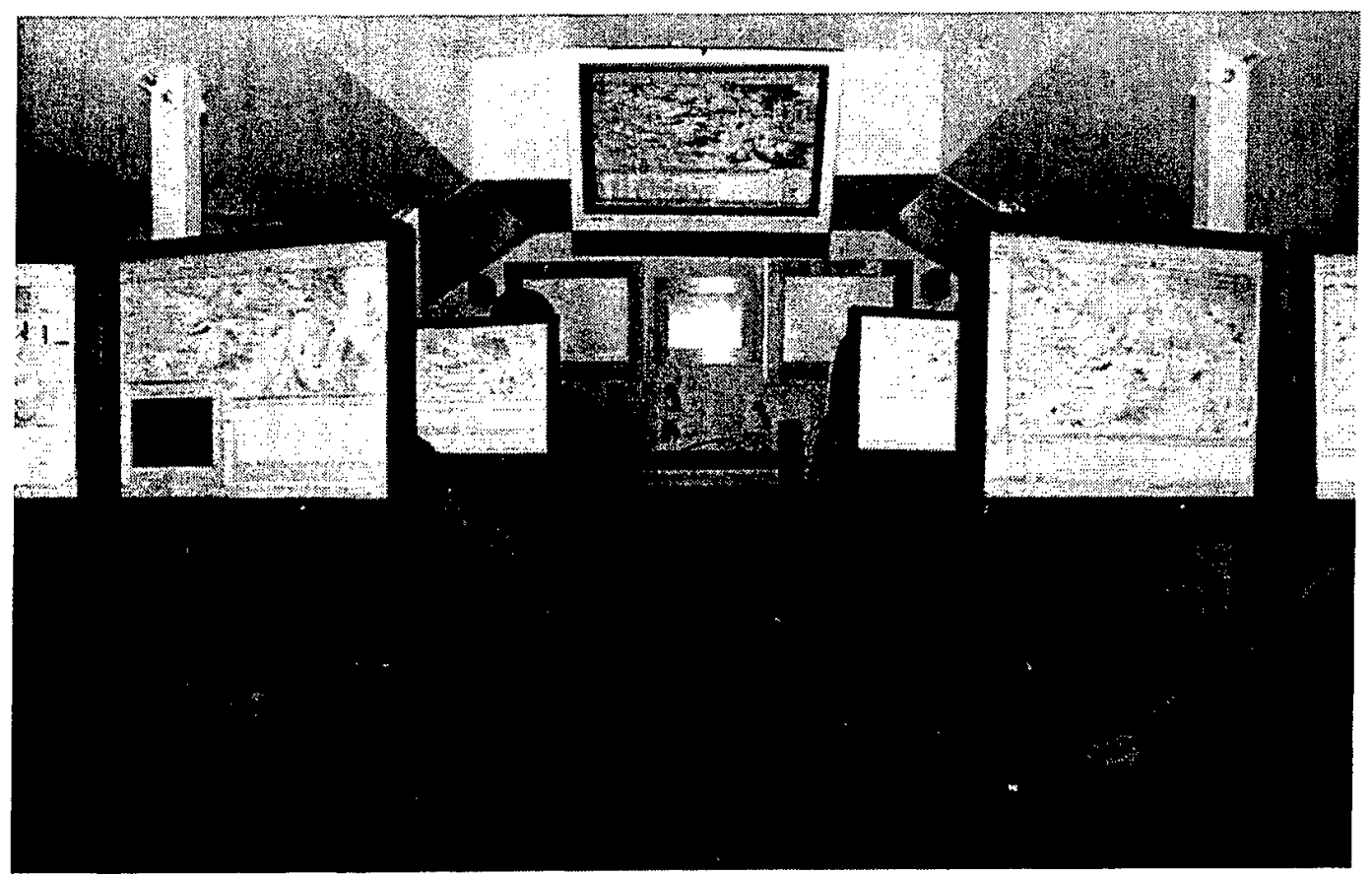

Figure 4. Command group participants in a surrogate command and control $\left(\mathrm{C}^{2}\right)$ vehicle.

\section{Description of the Command and Control $\left(C^{2}\right)$ Interface}

This section provides a brief description of the prototype $C^{2}$ system with a focus on individual and networked sensors for BCV 101 training development.

Figure 5 provides a sample display on the $C^{2}$ interface. Each $C^{2}$ workstation affords dual displays which are identical and redundant. However, each display can be independently configured by the user to support $\mathrm{C}^{2}$ requirements for different duty positions as well as user preferences. For the FCS $C^{2}$ program, the $C^{2}$ interface provided a near real-time common operational picture of the battlefield situation across the command group, such as the Deliberate Attack mission against an enemy battalion shown in Figure 5. The $C^{2}$ interface served as the primary means by which the command group performed basic $\mathrm{C}^{2}$ functions. For BCV 101, the $\mathrm{C}^{2}$ interface provides participants and training developers the ability to task sensor platforms and receive information collected from a mix of individual and networked sensors. 


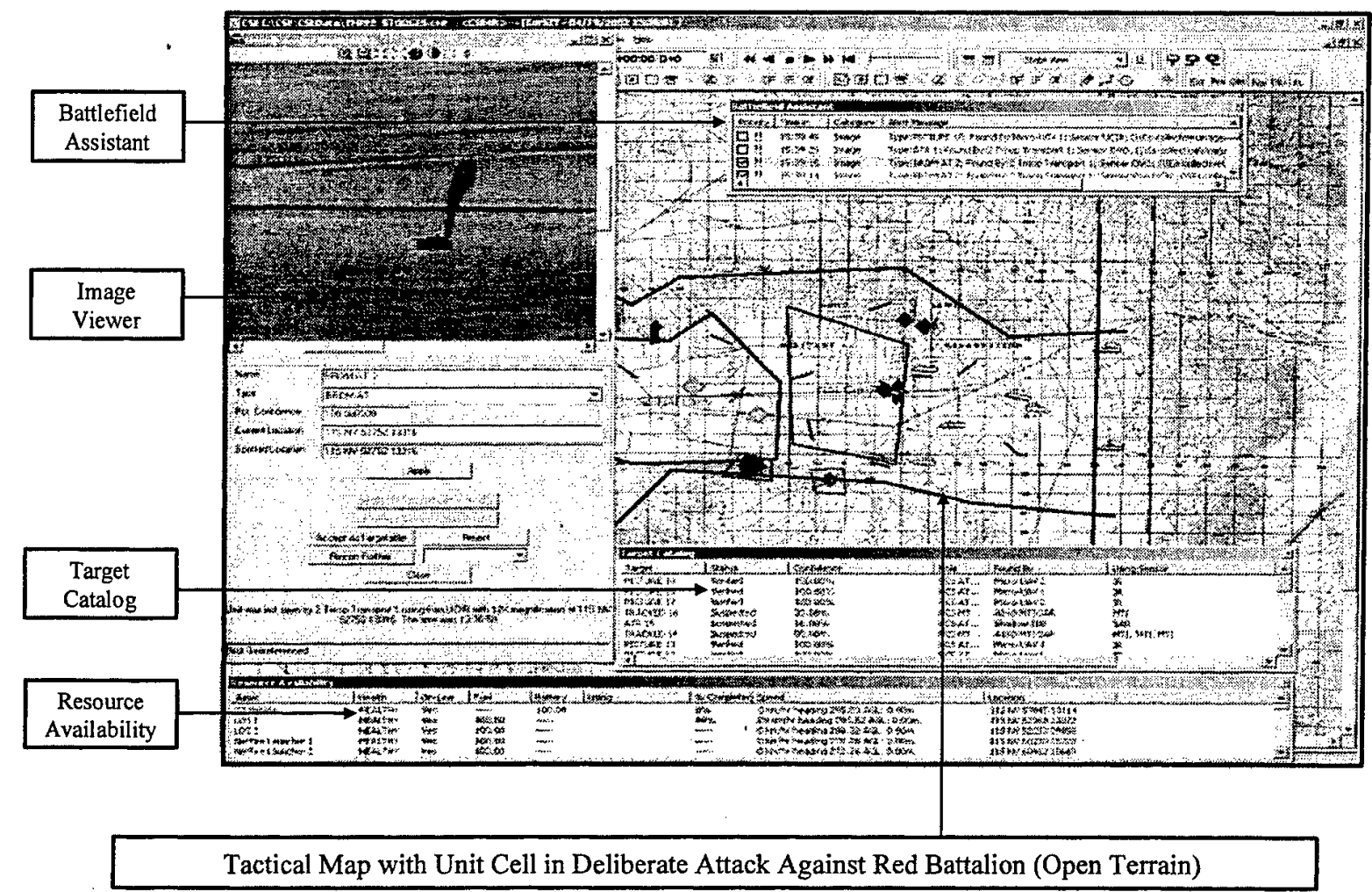

Figure 5. Sample view of the command and control $\left(C^{2}\right)$ interface.

The $\mathrm{C}^{2}$ system was developed to be compatible with virtual simulation, namely Distributed Interactive Simulation (DIS). Virtual simulation allows users to interact with elements of the friendly force, the threat force, civilian entities, and a digital terrain data base. The Army has determined its principal form of virtual simulation will be One Semi-automated Forces (OneSAF) Objective System (OOS). Currently, the $\mathrm{C}^{2}$ system is compatible with OneSAF Testbed Baseline (OTB) with plans to migrate to OOS when fielded.

As indicated in Figure 5, the $\mathrm{C}^{2}$ system provides a relatively standard interface design composed with windows, icons, menus, and pull downs (WIMP). The four open windows on the tactical map shown in Figure 5 indicate some of the $C^{2}$ system's advanced functionality. Overall, these and numerous other tools and features could be opened, configured, and used through either display at the $\mathrm{C}^{2}$ workstation. Features available from the four open windows are briefly described below:

- Battlefield Assistant provides information regarding various alerts that participants could tailor to their information requirements and activate. For example, alerts could signal the participants when a previously identified and tracked friendly, enemy, or neutral vehicle had crossed a phase line or entered a named area of interest (NAI).

- Image Viewer displays target images for human target recognition (HTR) and battle damage assessment (BDA). Image Viewer allows participants to input or revise the information associated with icons on the map including affiliation (e.g., friendly, enemy, neutral), type (e.g., tank, artillery), and status (e.g., suspected target, dead target). 
- Target Catalog allows participants to input or revise information associated with enemy targets including what friendly sensor(s) identified the target, when the target was identified, and the location and route of the enemy target.

- Resource Availability is used to access and revise information on friendly Unit Cell assets including operational status, available fuel, and current speed and location.

Certain tools in the $\mathrm{C}^{2}$ interface enable the tasking and re-tasking of individual and networked sensors for information collection, presentation, and decision-making. Figure 6 provides a sample of sensor tasking information entered on the $\mathrm{C}^{2}$ interface including a Restricted Operating Zone (ROZ), UAV routes, and NAIs. The ROZ defines where UAVs may fly without requiring airspace coordination with other units also conducting flight operations. The routes depict UAV paths to and through the NAIs. The NAIs serve to focus intelligence assets into a limited area where enemy elements are suspected, predicted by enemy doctrine, or previously reported. Although Figure 6 and other interface figures may appear here in black and white, the $\mathrm{C}^{2}$ interface uses colors to depict routes, areas, and sensor platforms. Color codes consistently relate sensor platforms, routes, and coverage areas to help differentiate sensor taskings.

Many of the graphic control measures for the $\mathrm{C}^{2}$ interface are "smart" graphics. For example, the $\mathrm{C}^{2}$ system encodes the NAIs entered by the user to coordinate and control sensor taskings, such as a microUAV tasking across a series of NAIs. Similarly, the $\mathrm{C}^{2}$ system supports the user by automatically checking ROZ-to-NAI visibility, or estimating the time required for SAR coverage of an NAI, and then providing automated feedback for user approval or adjustment.

The lower portion of Figure 6 depicts a tasking matrix, by sensor platform and time, to help manage sensor taskings and avoid conflicts. The four tasking bars shown in Figure 6 provide information on tasks entered for the Shadow 200 and three microUAVs. The tasking matrix combined with the sensor graphic control measures show how the coverage provided by each sensor supports and complements that of the other sensors. This may mean that different sensors, possibly on different platforms, will provide dual or overlapping coverage of the same area to detect and confirm the presence of enemy elements at a particular location.

The $\mathrm{C}^{2}$ system automatically updates the common operational picture across all $\mathrm{C}^{2}$ interfaces. For example, sensor taskings or control measures entered by any user are automatically shared with all other users. Any user can modify another user's inputs to include re-tasking another's tasks. Users can also save their interface inputs into files, sometimes called planning files. Planning files may be routinely stored on the system and later used to initiate a new plan or modify an old plan.

Of special interest, the planning files can be used to animate the plan providing users a preview or rehearsal of the plan. With animation, sensors and other friendly platforms move across the battlefield at user-defined speed to provide a visualization of the plan, including a way of checking total coverage of assigned reconnaissance objectives. Plan animation does not link to an OTB simulation of threat forces, and animated friendly elements will not detect or act on enemy elements. When downloaded to OTB, however, planning files can be used to initialize a virtual simulation exercise in which the friendly force elements interact with enemy elements. 


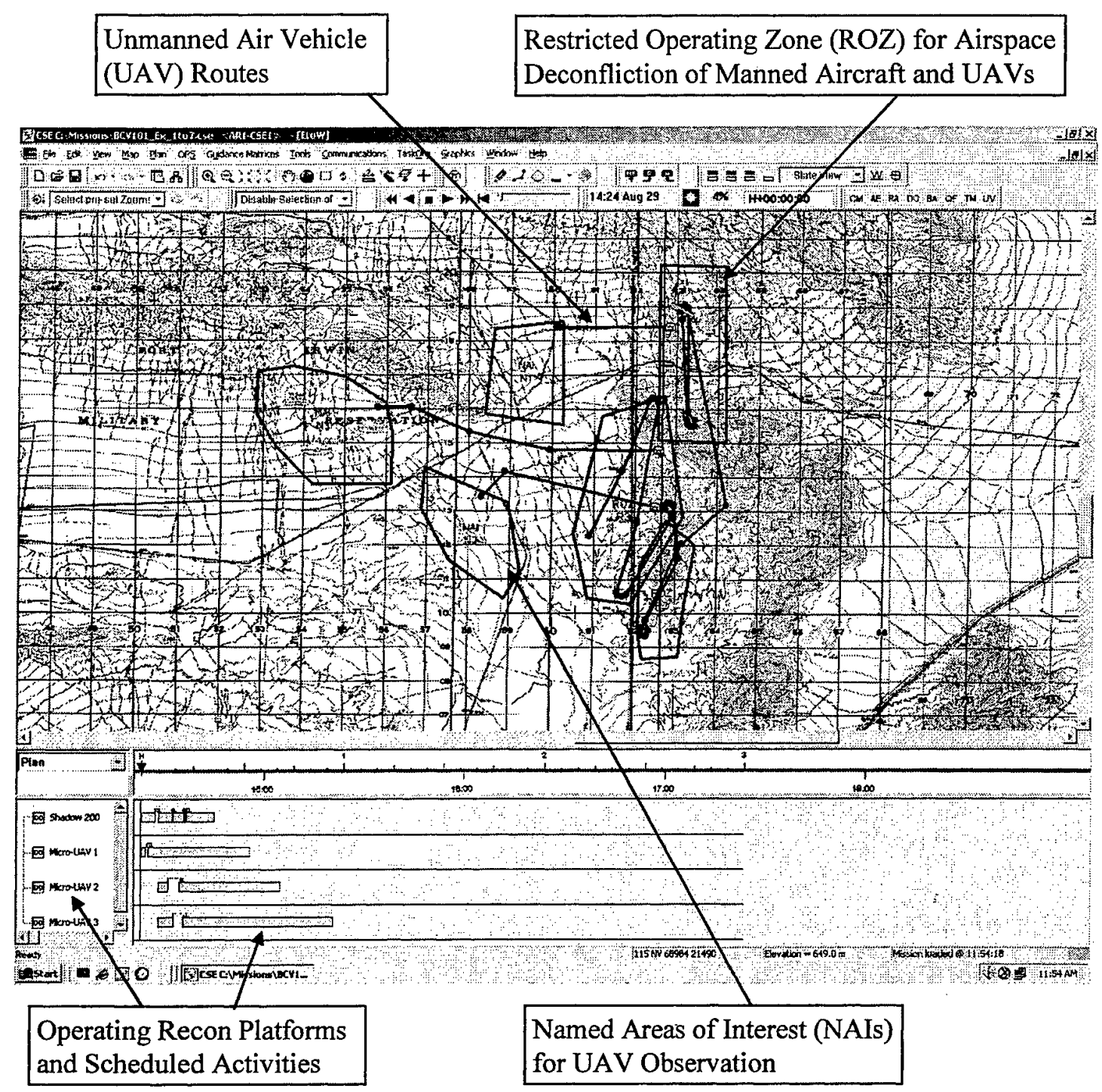

Figure 6. Command and control $\left(\mathrm{C}^{2}\right)$ interface with sensor tasking information.

Figure 7 shows a snapshot view of animation during a typical BCV 101 exercise with microUAVs en route or on-station at their assignments, waiting cueing from Shadow 200 detections. In animation mode, entity taskings can be run faster than real-time, repeated, adjusted, and saved for later use or sending to others.

For the FCS C $\mathrm{C}^{2}$ program, multiple courses of action for a mission were planned, saved, and then played in animation to aid decision-making. The final course of action plan file was adjusted prior to execution based on any incoming new enemy intelligence and then downloaded to OTB to begin mission execution in virtual simulation. 


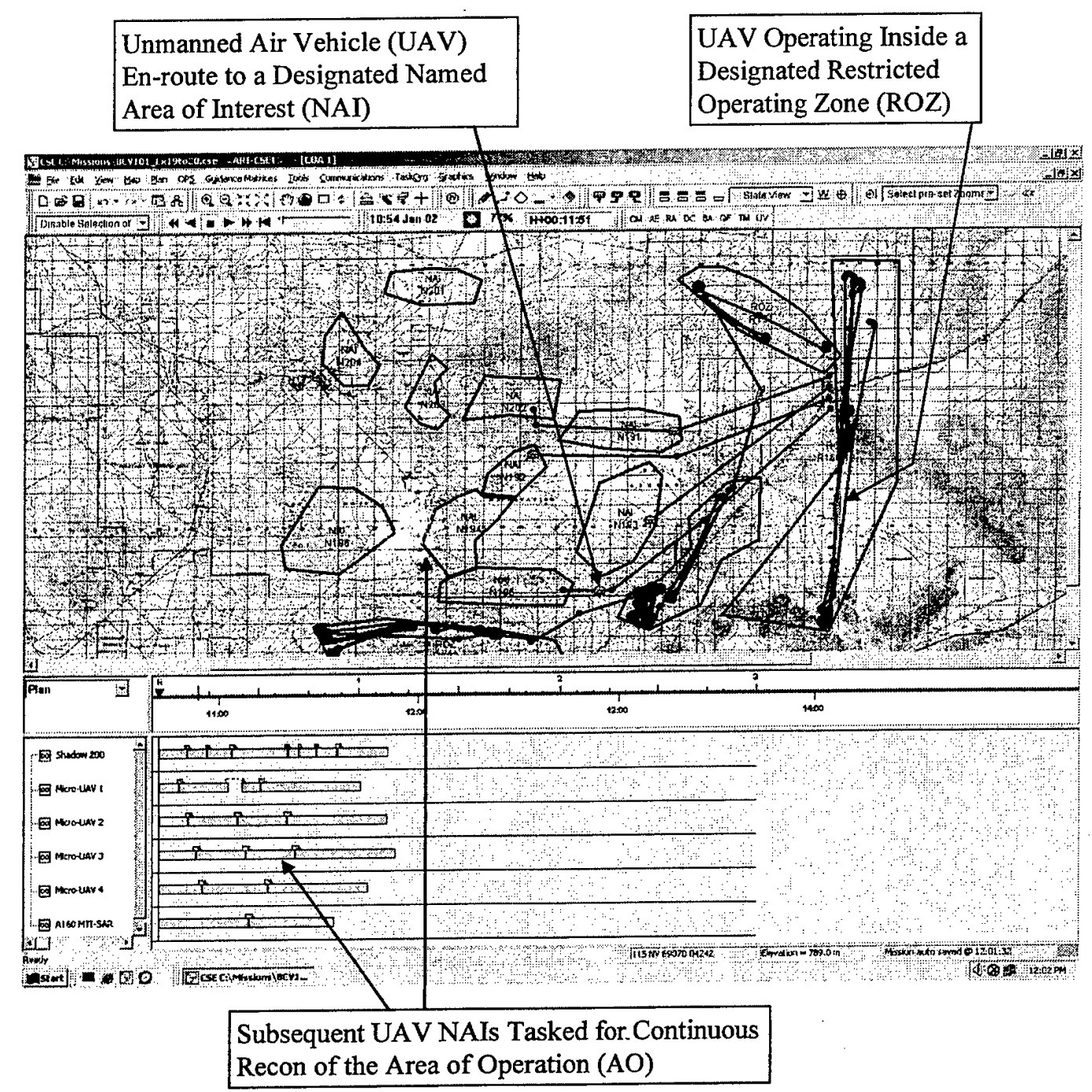

Figure 7. Animation snapshot with microUAVs en-route or on-station awaiting next tasking from Shadow 200.

\section{Construction of the Sample Exercises}

This section describes the research team's efforts to construct sample exercises, or visualization tasks, for the BCV 101 training program. Based on a COFT-like training model, the goal was to develop a small set of progressive exercises designed under controlled and deliberate task conditions with automated feedback relating task performance to standards. Realistically, the research team expected this initial effort at exercise development would help to identify and address, at least partially, some key technical challenges in developing BCV 101 training and embedding training, as required by FCS (DA, 2003b).

Accordingly, the 20 exercises in Table 2 were constructed in a manner compatible with the prototype $C^{2}$ system and OTB virtual simulation. Overall, exercise development was a promising start on the extended process of developing a working example of embedded training. However, technical limitations in the $\mathrm{C}^{2}$ system and OTB required workarounds that fell short of 
the BCV 101 training design and embedded training objectives, as discussed in this section. The Training Implications section that follows provides supplementary discussion and summarizes lessons learned on technology dependent training.

\section{Train-the-Trainer}

Several train-the-trainer sessions preceded exercise development. The BCV 101 research team based at Fort Knox, KY, traveled to Fort Monmouth, NJ, in September 2003 to observe two days of participant training during Experiment $4 \mathrm{~A}$ under the FCS $\mathrm{C}^{2}$ program. Coordination with DARPA and CECOM on the BCV 101 effort was conducted during the visit. The need for a scaled-down version of the $\mathrm{C}^{2}$ system at Fort Knox for BCV 101 was identified, and a scaled $\mathrm{C}^{2}$ system was delivered to ARI at Fort Knox in December 2003. During its installation, two days of training were provided by a CECOM support team. The first training day was directed at technical support of the scaled $\mathrm{C}^{2}$ system. On the second day, instruction focused on sensor capabilities and exercise development issues of concern to the BCV 101 research team.

For the next several weeks, the primary training developer for BCV 101 engaged in hands-on learning with a focus on developing the initial set of 20 exercises. During this time, many of the necessary procedures to program and manipulate the $\mathrm{C}^{2}$ system for exercise development were identified and established. Key procedures included how to adjust sensor locations, routes, and observable areas with respect to enemy locations in order to ensure sensor feedback in the time allocated for each exercise. As technical limitations were encountered, the training developer also started to identify potential workarounds in an effort to meet BCV 101 design requirements.

\section{Major Technical Limitation}

Exercise development quickly surfaced some key training advantages and disadvantages with the $\mathrm{C}^{2}$ system and OTB. Most technical limitations were surmounted by workarounds. However, the prolonged time to shift from one exercise to the next exercise forced a re-design described below. Future development efforts should address this limitation, as discussed in the Training Implications section.

By design, short (5-10 minute) exercises were to provide progressive, part-task training with deliberate practice opportunities and direct, immediate feedback. At an average of six minutes per exercise, including a minute post exercise feedback, it was estimated the 20 sample exercises could be completed in two hours. By comparison, COFT training time is allocated in one/two-hour slices for reasons applicable to BCV 101 training. Rationales for the COFT time slices include training principles, such as avoiding diminishing returns from individual and crew inattention, and practical concerns such as maximizing the throughput of individuals and crews for COFT required training.

However, the time to initialize the next BCV 101 exercise was almost equivalent to the 510 minutes allotted per exercise, based on multiple trials by the primary training developer. The time to start the next exercise was primarily attributed to OTB re-initialization requirements. Starting the next exercise required bringing down and then re-starting or re-initializing the two 
OTB servers representing the friendly and enemy elements in the upcoming exercise. Moreover, the trainer was required to perform an exacting and time-consuming set of computer procedures to re-initialize the next exercise. The trainer also needed to conduct a post-exercise feedback session or after action review (AAR) of the just-ended exercise with one or more participants.

In sum, the total time from start of one exercise to start of the next was estimated at not less than 15 minutes, given the current $C^{2}$ system and OTB configuration. The addition of a second support person to take down and bring up the configuration between exercises might lessen the total exercise time to 10 minutes, for the shortest exercises. The estimated costs in time and manpower were considered unacceptable for BCV 101 or future embedded training programs, so an exercise bundle approach was adopted to continue exercise development.

\section{Exercise Bundles}

A compromise to the $\mathrm{BCV} 101$ training design was devised to temporarily mitigate the time problem in starting a new exercise. A compromise solution sorted the 20 individual exercises into five exercise bundles, as specified in Appendix $\mathrm{C}$. The bundle approach required crafting the individual exercises into a series of interrelated exercises. It also required developing and providing to the user a more overarching tactical framework to relate the exercises within each bundle. The use of bundles did reduce the number of times required to reinitialize OTB and the $\mathrm{C}^{2}$ system during a training session.

It was estimated that participants could complete even a relatively large bundle of 6-8 exercises and a post exercise feedback/coaching session in about one hour. Exercises within a bundle comprised a related series of sensor tasks. However, the use of exercise bundles versus discrete exercises weakened the link between tasks, conditions and standards for each exercise, limited repeated practice opportunities, and complicated proficiency-based training progression.

\section{Exercise Overview}

The basic design for each exercise paired a Shadow UAV for early detections with a microUAV for subsequent recognition and identification by the participant. More complex exercises added an A160 UAV platform for additional detections, and multiple micro UAVs for additional recognition and identification tasks.

Initial exercises addressed individual sensors targeted at more detectable enemy entities, such as single, stationary, wheeled or track vehicles in open terrain. The initial exercises were also designed to provide a basic understanding of the $C^{2}$ interface or tactical display, particularly sensor related data and information. Intermediate exercises targeted less detectable enemy, such as dismounts in more closed terrain, or enemy vehicles mixed with civilian vehicles. Advanced exercises included a combination of less detectable entities, more sensors, and more exacting recognition and identification tasks.

All exercises provided simulation-based feedback on the process and outcome of sensor employment during the exercise. Process feedback included visual depiction of dynamic sensor footprints or coverage areas, and outcome feedback included automated alerts and data on sensor 
detections and sensor images received. Feedback after exercises was provided by the trainer rather than the $\mathrm{C}^{2}$ system, as discussed in the Training Implications section under Performance Feedback.

In sum, the 20 exercises were divided into five exercise bundles with 3-7 exercises of progressive difficulty per bundle. Time required to complete each bundle was estimated at 30-60 minutes to allow enough time for sensor detections, sensor cross-cueing, sensor images received, participant assessment of sensor images, and feedback to the participant. More detail on the sample exercises is provided in Table 2 and Appendix C.

\section{Development Process}

Development required iterative refinement of draft exercises and bundles to match the BCV 101 training objectives, to the extent possible. A valuable resource for development is the plan animation tool and the ability to store and modify draft exercise files, as described earlier in the section $C^{2}$ Interface Description. The training developer could repeatedly review draft exercises in the animation mode to check visually the sensor taskings for individual or networked sensors including assigned routes and coverage. Visual review of sensor coverage is facilitated by the $\mathrm{C}^{2}$ system's ability to display sensor fans or "footprints" as the sensors move along the routes assigned. In addition, the training developer could input the known location of enemy elements for an exercise directly on the $\mathrm{C}^{2}$ interface's tactical map to supplement visual review of sensor coverage.

During the next phase of development, the training developer verified sensor coverage with automated feedback from OTB's virtual simulation. To "run" the exercise, the training developer downloaded the friendly exercise file to OTB from the $\mathrm{C}^{2}$ interface and initialized a complementary OTB enemy file previously built to match the threat task conditions. If the exercise files for friendly and enemy elements were correct, this simulation-based "run" for the exercise bundles would result in early detections by larger sensor platforms followed by the expected sensor images from microUAVs. If not, the training developer would iteratively revise the draft exercise files until task conditions for the exercise were correctly set, and then save the final exercise or exercise bundle.

Additional detail on the exercise development process is provided in the following paragraphs for BCV 101 documentation, and potential use in other training development efforts. Exercise development deliberately positioned the enemy array to ensure it could be detected by the air sensors in the time allotted for the exercise, or series of exercises within a bundle. The NAIs were used as a control mechanism to focus the reconnaissance effort in accordance with doctrinal guidelines. Developmental review of the exercises indicated the NAIs should be limited to four square kilometers in area, given the time allotted per exercise.

For each exercise bundle, the radar capable Shadow 200 UAV or the A160 were carefully positioned with respect to pre-identified ROZs and NAIs. At the start of each exercise, these radar sensor platforms would move to the areas assigned and begin their search. As noted, the MTI and SAR sensor systems onboard these platforms designate the locations of detected elements on the battlefield. These detections automatically generate "unknown" icons on the $\mathrm{C}^{2}$ 
interface, as shown in Figure 8. They also generate complementary warnings and messages respectively in the Battlefield Assistant and Target Catalog windows shown in Figure 5.

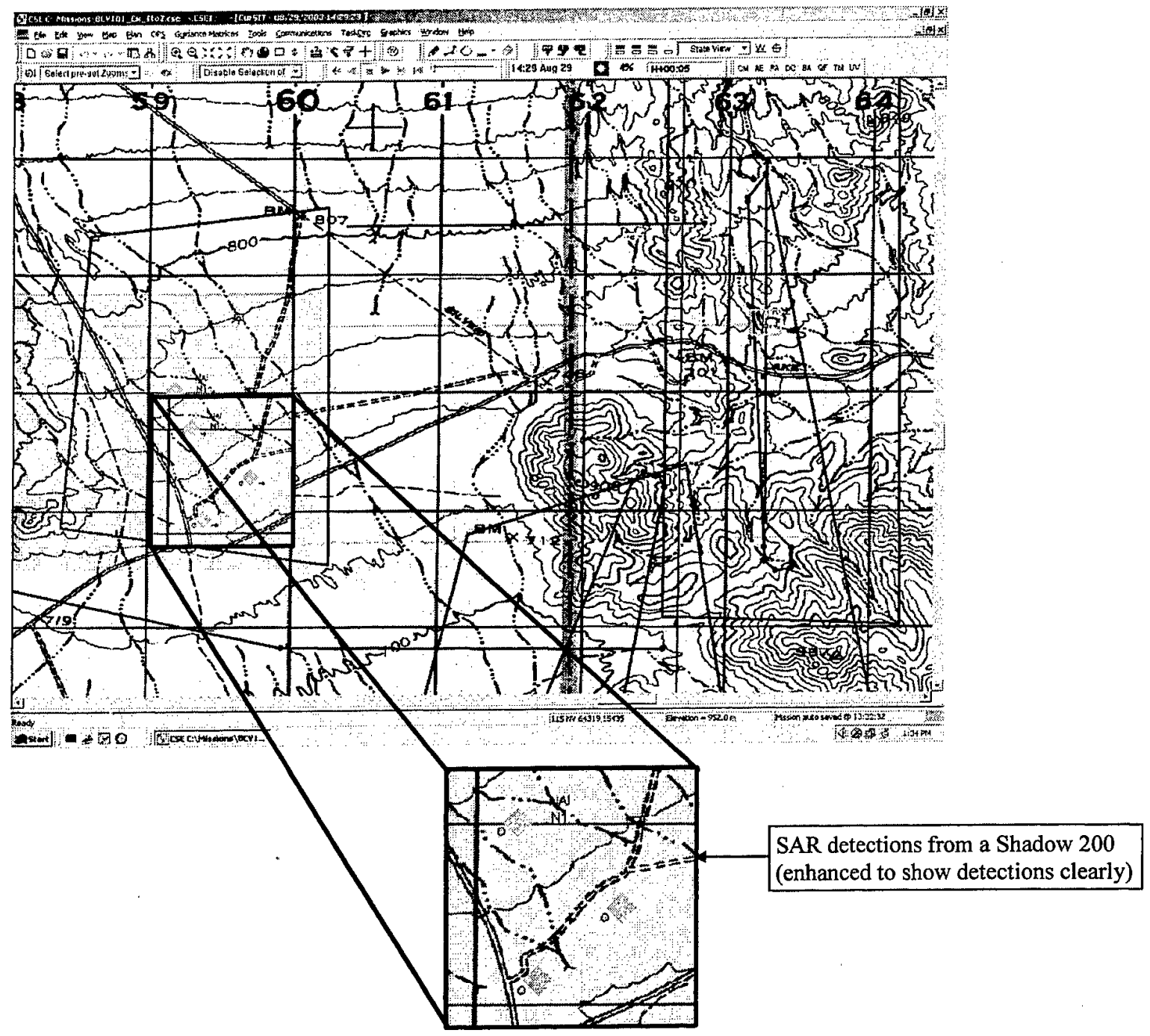

Figure 8. Sample of synthetic aperture radar (SAR) detections.

Exercise development stressed that an integrated reconnaissance plan, even at the individual exercise or task level, should skillfully balance and complement the capabilities of the available sensor assets. For example, the radar equipped sensors onboard the Shadow 200 and A160 platforms covered far larger areas of the battlefield faster than the microUAVs. In fact, the MTI footprint was larger than the entire area of operations assigned to the company level participants in the FCS C ${ }^{2}$ experiments and the participants anticipated for BCV 101. The SAR footprint was substantially smaller than MTI, but it could sweep across designated NAIs much faster than a microUAV.

A tactics, techniques, and procedures adapted for BCV 101 from the FCS $\mathrm{C}^{2}$ participants was to task the microUAVs based on radar detections. This TTP provides an example of 
exploiting automatic sensor cross-cueing made possible by the sensor network represented in the prototype $\mathrm{C}^{2}$ system. Such TTPs are particularly appropriate with microUAVs that provide only snapshot images versus streaming video, as currently modeled by DARPA for the FCS $\mathrm{C}^{2}$ program to avoid potentially unrealistic outcomes. In sum, the microUAV models available were slow movers with a small "soda straw" footprint that returned only snapshot images taken at designated locations.

After reaching the designated location of a detected element, microUAVs begin automatically to return snapshot images at that location. An example of the raw output from a microUAV, a good sensor image of a stationary enemy tank, is shown in Figure 9. Moving targets are particularly difficult to capture in a microUAV snapshot image, in part because the entity may have moved from the designated location used to trigger the snapshot. Exercise development positioned the microUAVs sequentially to provide pictures of all the radar detections in a particular NAI. As the exercises progressed in difficulty, including moving entities, the quality of the images returned by the microUAVs often dropped appreciably.

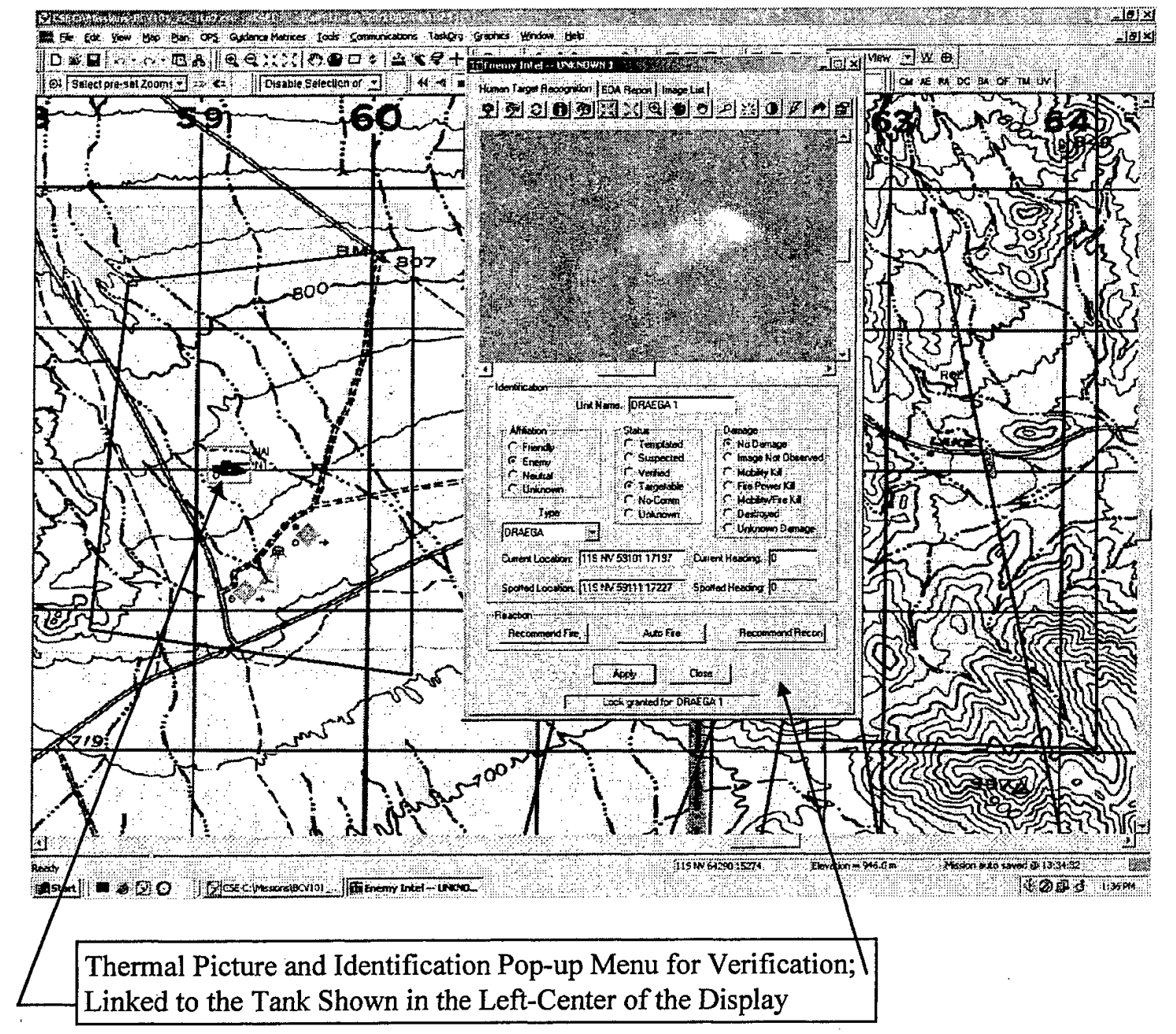

Figure 9. Command and control $\left(C^{2}\right)$ interface with microUAV sensor image. 
The primary task of the participant during the 20 exercises was to examine and evaluate the raw sensor output from the microUAVs. Recognition and identification of the images received by the participant included: indicating the enemy/friendly status of the entity, vehicle type, and vehicle status as well as assessing any battle damage depicted, and associating the image to a templated (if any) enemy position.

\section{Training Implications}

This section briefly reviews some key implications on technology dependent training that apply to the BCV 101 effort, and may apply to the Army's ongoing development of embedded training for FCS. More extensive reviews of training implications for FCS are available from ARI (e.g., Campbell, Throne, Black, \& Lickteig, 2003; Carnahan, Lickteig, Sanders, \& Durlach, 2004; Throne \& Burnside, 2002). Table 3 summarizes the training implications identified and discussed in the remainder of this section.

Table 3

\section{Summary of BCV 101 Training Implications}

Training Challenge

- Accept that FCS raises warfighters' tactical and technical skill requirements.

- Recognize training is the glue that will hold FCS and the Future Force together.

Training Design

- Structure training to directly relate tasks, conditions, and standards.

- Shift training from procedural to conceptual skills as automation emerges.

Training Development

- Ensure proactive collaboration between the developers of training and technology.

- Immerse training developers in a user-based $C^{2}$ system development process.

- Provide training developers with authoring tools in $\mathrm{C}^{2}$-based training systems.

- Develop methods to adapt training as fast as training requirements change.

Training Delivery

- Acknowledge the imposing technical challenges to technology dependent training.

- Address now the requirements for tomorrow's embedded training with simulation.

Training Feedback

- Provide the feedback instrumental to learning; practice without feedback is insufficient.

- Stress measurement methods for post-exercise feedback and gated training.

Note: "FCS" = Future Combat Systems. "C ${ }^{2}$ system" = command and control system.

\section{FCS Training Challenge}

Training requirements for FCS-equipped Soldiers with highly automated and interdependent network-based systems may entail unprecedented levels of tactical and technical expertise (Lickteig et al., 2003). More automated systems can relieve routine tasks, but often raise the demand to understand the decision rules and parameters designed into the automation. 
During Experiment 3 in the FCS C ${ }^{2}$ program, for example, the Shadow UAV tended to "wander off" toward enemy elements under Auto Recon and be destroyed, a critical loss to the command group's See First capability. This unintended consequence of high automation was due to misunderstood reconnaissance parameters, information overload that limited monitoring, and lack of an effective human override to abort an automated routine in a timely manner.

Understanding the limits and strengths of FCS technology was a severe challenge even for relatively expert participants. After the FCS C ${ }^{2}$ Experiment 4, experienced participants, many of whom had participated in over 40 mission runs across four experiments, expressed strong concerns about training and their ability to exploit fully their FCS capabilities.

Training is the glue that will hold FCS and the Future Force together. ARI's conclusions on the $\mathrm{FCS} \mathrm{C}^{2}$ research stressed basic but far-reaching recommendations to improve the training of individuals and units in future FCS organizations, and particularly command groups (Lickteig et al., 2003). The BCV 101 effort addressed, in part, one of the recommendations: Develop progressive simulation-based training exercises directed at individual tactical and technical skills and the operational consequences of automated systems.

\section{Training Design: Structured Training}

A structured training approach develops and sustains performance proficiency and improves knowledge, skills, and abilities (Campbell, Quinkert, \& Burnside, 2000). Structured training is characterized by an incremental series of exercises often situated in a simulated environment to provide task realism and performance feedback. The essence of structured training is a training approach that directly relates tasks, conditions, and standards. The BCV 101 training design emulated a structured training approach with a set of progressive exercises designed under controlled and deliberate task conditions with automated feedback relating task performance to standards.

The bundle approach adopted to overcome delays between exercises was a compromise in the BCV 101 design based on structured training. Exercise bundles weakened the close link between task conditions and standards, limited the opportunity for repeated practice and contextspecific feedback, and complicated development of a gate pass structure. For instance, exercise bundles forced the initial location of microUAVs immediately near the NAIs to respond rapidly to cross-cue detections and provide sensor images. As a result, the interface quickly became more cluttered and demanding than desired for initial exercises. Although such a challenging environment is anticipated for Soldiers in FCS units, a progressive approach to skill acquisition provides initial exercises that are less challenging. It also models the Army's crawl-walk-run approach to training.

\section{Training Development: Technical Collaboration and Authoring Tools}

Training development for new systems is often reactive. How can you develop training on a system that does not yet exist? Even when initial versions of a new system are available, they are often so incomplete, so inadequate, that training development is a frantic mix of catch up and workarounds. For Experiment 3 in the FCS C ${ }^{2}$ program, for example, 13 new features 
were added to the prototype $\mathrm{C}^{2}$ system. The new features, such as an Attack Guidance Matrix (AGM) that generates fires based on sensor-to-shooter networks, automated numerous timeconsuming and time-limited tasks. However, these features created new training requirements and they shifted the focus of training from procedural to conceptual skills, as task performance shifted from doing to understanding and controlling what was automatically being done.

Proactive collaboration between the developers of training and technology is the only way to efficiently and effectively develop the technology dependent training required for FCS. Moreover, the burden is on training and tactical experts to provide to the technical experts identified training requirements and proposed training designs to meet those requirements. In important ways, this type of collaboration is ongoing with FCS system and training development (J. Shiflett, personal communication). However, too often the training developers are not adequately positioned or immersed in the system development process.

System development for the Army is a user-based process. The FCS $\mathrm{C}^{2}$ program provides an excellent example of how the design of a $C^{2}$ system is best determined by expert users who repeatedly employ and modify a prototype $\mathrm{C}^{2}$ system in a futuristic operational environment. It is also a good model of how to immerse training developers into the system development process, into the formative dialog that shapes a $C^{2}$ system. This process model is particularly important for FCS embedded training in which the $\mathrm{C}^{2}$ system also serves as a training delivery method. As a sample result, the training requirement for basic visualization skills was identified and the BCV 101 effort initiated to provide a COFT-like approach for training sensor exploitation.

The BCV 101 effort also underscores the need for authoring tools and methods by which trainers can adapt a $C^{2}$ system to meet training requirements. Training development is an iterative process in which the design of training programs and supporting exercises is best accomplished across a series of design-develop-test-redesign cycles. Moreover, the requirement for simulation-based training extends the need to develop training on a $C^{2}$ system to include the supporting simulation, namely OTB and OOS. Over a decade ago, ARI developed and applied a powerful set of training tools compatible with an earlier $\mathrm{C}^{2}$ system prototype and OTB virtual simulation (Atwood, Winsch, Quinkert, \& Heiden, 1994). Similar and even more powerful $C^{2}$ system- and simulation-based training tools are needed for FCS training development.

The $\mathrm{C}^{2}$ system used for BCV 101 was an adopted system originally developed for use in FCS C $\mathrm{C}^{2}$ research efforts, and as such did not have the tools, features, or documentation needed for developing the subject training program as designed. The available tools adapted to support training development included: the animation files for reviewing and revising draft training exercises, smart graphics for controlling and assessing sensor taskings, color-coded sensor fans or footprints for visualizing sensor coverage, and simulation-based process and outcome feedback on sensor deployment.

However, the BCV 101 goal of providing perceptually augmented task conditions and feedback for the user/participant was constrained by technical limitations and the tools available. The $C^{2}$ system provided no interface tools by which the training developer, or the participant, could readily adjust or modify the system's current color codes or patterns for representing 
sensor platforms, routes, and coverage areas. Additionally, any attempt to change color codes or system software by the BCV 101 research team was deemed inadvisable by the technical developers of the FCS $\mathrm{C}^{2}$ system due to system complexity. To develop and refine training, the $\mathrm{C}^{2}$ system should be sufficiently modularized to permit modifications by training developers. Such modularization may begin by creating a "Training Mode" in the $\mathrm{C}^{2}$ system, but a "Training Development Mode" is also needed.

More responsive tools for training developers are also needed to provide simulationbased training on $\mathrm{C}^{2}$ systems, as required by FCS. Such tools are projected with the fielding of OneSAF (OneSAF, 2004); however, the tools currently available with OTB did not support the BCV 101 requirement for minimal duration and re-initialization requirements between exercises. The simulation system also did not support an adaptive sequencing of exercises or gates with decision points for subsequent levels of training.

\section{Training Delivery: Simulation-Based Embedded Training}

A key performance parameter (KPP) for FCS is embedded training delivered by an advanced $\mathrm{C}^{2}$ system compatible with OneSAF Objective System for virtual simulation (DA, 2003b). A fundamental value of virtual simulation is that it affords participants and trainers a performance medium that models interactive conditions, behaviors, and outcomes. To provide an exemplar of embedded training for FCS, the BCV 101 effort focused on the development of basic visualization training delivered by a prototype $\mathrm{C}^{2}$ system linked to OTB.

A key finding is that the technical challenges to technology dependent training are imposing. This is not a new finding, but it is one of increasing relevance as the Army transitions to FCS and the Future Force. By design, FCS poses an extraordinary alliance of humans and machines - an interdependence that significantly impacts the small unit and the individual Soldier. The impact is positive, as advertised, but potentially quite negative if the humanmachine fit is not made or fails. Training will prove essential to maintaining and sustaining a forceful human-machine alliance.

However, a major technical limitation encountered in BCV 101 exercise development was the prolonged time required to shift from one exercise to the next exercise. The time to start the next exercise was primarily attributed to OTB re-initialization requirements. Starting the next exercise required almost the same amount of time as the conduct of the exercise, and required the trainer to perform an exacting set of computer procedures between exercises. Ideally, embedded training would provide rapid and controlled progression through exercises by the participant, particularly for individual training.

Technical limitations not only impacted training efficiency with prolonged shifts between exercises, but also training effectiveness as envisoned in the BCV 101 design. As discussed under Training Design implications, exercise bundles undermined the design's structured approach to training, limited practice, and complicated proficiency-based training progression. As discussed in the following section, providing the performance measurement and feedback considered instrumental to training also requires overcoming technical limitations and effectively leveraging technical capabilities. 


\section{Training Feedback: Performance Measurement and Perceptual Augmentation}

Process measures of learning are needed to provide the feedback instrumental to learning. In many real world settings, the "measured" comparison between actual and desired performance may be so obvious, so intuitive, that it belies any measurement requirement. In more artificial and complex performance settings, however, feedback is often less obvious and more difficult to interpret.

During FCS C 2 missions or "runs" with interdependent and highly automated technologies, performance feedback was too often missing and inadequate. Causes for many of the "problems" identified during a run were often unclear. Was it a shortcoming in the technology, the training, or the performers' TTPs? The BCV 101 training design stressed the importance of feedback during and after exercises. A design goal was to exploit the ability of digital technologies, such as $\mathrm{C}^{2}$ systems and simulation, to help solve many of the training challenges they create.

Feedback during the BCV 101 exercises provided simulation-based feedback on the process and outcomes of sensor employment. Process feedback included visual depiction of dynamic sensor footprints or coverage areas, and outcome feedback included automated alerts and data on sensor detections and sensor images received. For example, feedback on sensor coverage for a specified route includes visible sensor "footprints" moving across the tactical map and digital "readouts" on percent of NAI covered by time for a designated ROZ. Entering nonviable routes is not permitted by the $\mathrm{C}^{2}$ system, and they automatically result in a warning notice to the user when selected.

However, the prototype $C^{2}$ system provided limited and not easily modified mechanisms for improving feedback, particularly perceptual augmentation for sensor visualization and management. For example, visual feedback on sensor "footprints" was often almost invisible due to indiscriminate color codes, screen clutter, and human perceptual limits. Figure 10 depicts several of the sensor footprints that a user can turn on/off from a window on the $\mathrm{C}^{2}$ interface. However, the more detailed information presented within the relatively small footprints depicted is hard to discern, particularly when a larger map area is displayed. As a form of perceptual augmentation for the reader, Figure 10 also provides adjacent zoom views of the same sensor footprints below the interface.

Feedback after the 20 sample exercises was provided by the trainer rather than the $\mathrm{C}^{2}$ system. The $\mathrm{C}^{2}$ configuration at ARI-Knox does not currently include a data logger with the ability to collect and present exercise data for automated feedback. For future research on more automated performance measurement, a data logger can be added to the $\mathrm{C}^{2}$ configuration at ARIKnox. Meanwhile, the current BCV 101 effort focused on the design of measurement methods required for effective post-exercise feedback and a gated pass structure. Currently, the measures designed track the participant's recognition and identification of the sensor images received by enemy/friendly status of the entity, vehicle type, vehicle status, battle damage assessment, and relation to templated enemy position. 


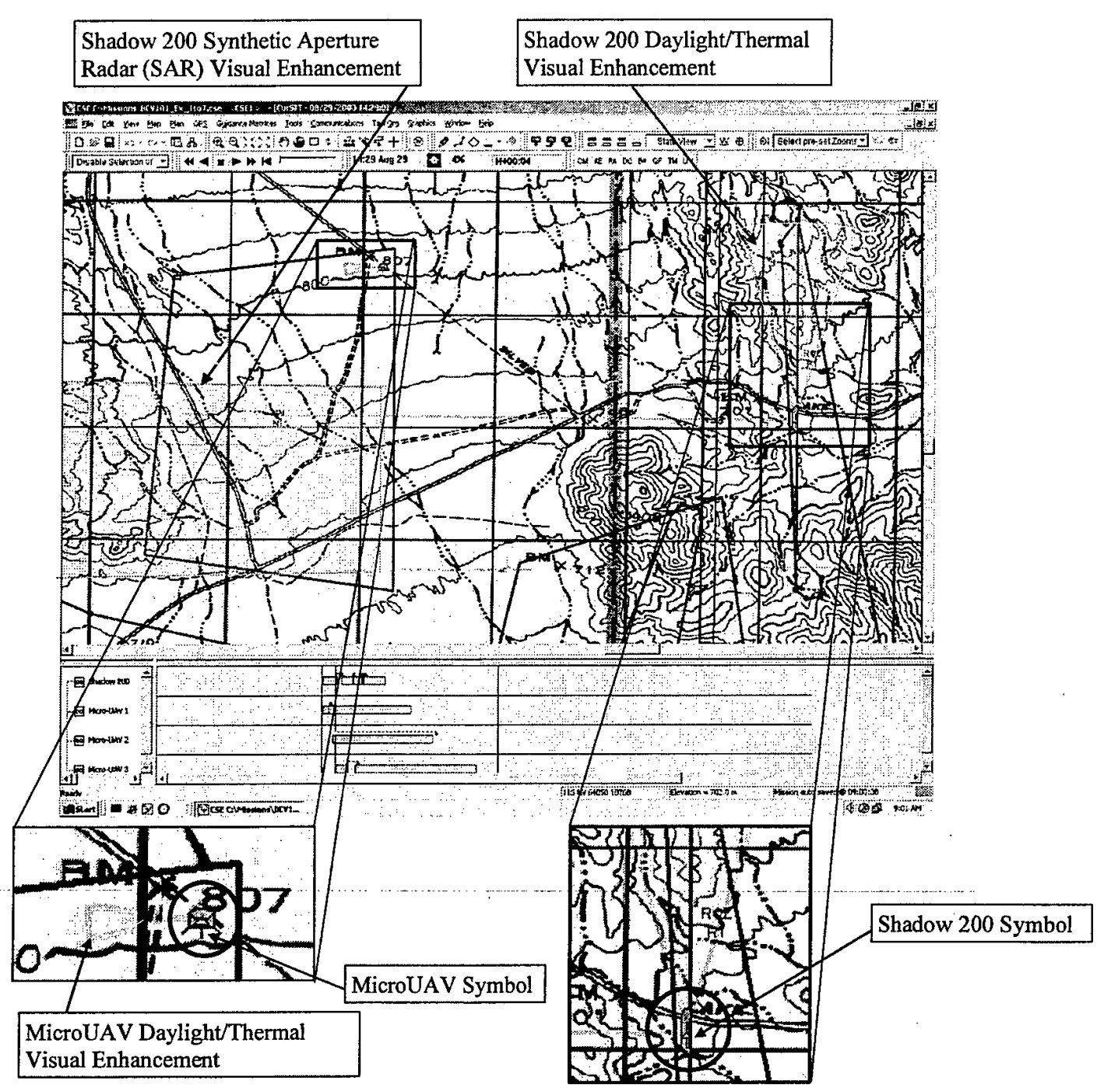

Figure 10. Visual enhancements of sensor coverage and footprint areas.

\section{Conclusions}

Training developers have long called for an integrated training and operational system. The concept may become a reality as the Army addresses embedded training as a "no kidding, no excuses" requirement for FCS (DA, 2003b). The goal of embedded training underscores the need for Soldiers to train as they fight in their operational systems. Coupled with simulation, embedded training also reinforces the Army's commitment to performance-based training.

Achieving the Army's goal of embedded training is a formidable task. It requires no less than a transformation in training that will occur only by sustained and cumulative effort. The concept of truly embedded training will only be realized if training developers and system developers work on a peer-to-peer basis from the initial conceptual design stages. Proactive research on the ways embedded training can and should be delivered will pave the way to the Future Force. Providing embedded training designs and programs at the earliest stages of system design is a training development requirement. 
Training and tactical experts bear the burden for communicating to system builders the training designs that are relevant and realistic for $\mathrm{C}^{2}$ systems in a virtual environment. Important lessons learned, ideas, critiques, and questions will not be addressed without early and sustained communication on substantive findings. Training and operations are merging, just as virtual and real worlds are, to support the Future Force. Having a short operations-to-training modification feedback loop, will best support the Future Force and meet the Quality of Firsts.

Overall, the BCV 101 effort provides a promising start on the extended process of developing a working example of embedded training to help meet the See First requirement. The design of the training program and exercises combines theory and technology to address an important and unmet training objective of the Future Force. One of the key products of this effort was the prototype training design for BCV 101 as an exemplar for FCS embedded training, but that design alone is incomplete. Results from the BCV 101 effort stress the need for $\mathrm{C}^{2}$ training systems to support such designs, systems that are rapidly configurable and focused to provide reinforcement of operational concepts and needs.

Based on lessons learned, the BCV 101 follow-on effort will extend and refine the training design and exercises required for networked sensor exploitation to meet the See First requirement. Future research should generate user-sanctioned embedded training designs on networked sensors through external evaluations. More generally, the BCV 101 follow-on effort should help forge the needed link between training development and $C^{2}$ system development to meet Future Force training requirements. The training objective for BCV 101 remains clear: Current Force small unit commanders have little experience with networked sensors on a regular basis - with the right training, their Future Force counterparts will routinely exploit them. 
References

Atwood, N. K., Winsch, B. J., Quinkert, K. A., \& Heiden, C. K. (1994). Catalog of training tools for use in Distributed Interactive Simulation (DIS) Environments (ARI Research Product 94-12). Alexandria, VA: U. S. Army Research Institute for the Behavioral and Social Sciences.

Campbell, C. H., Throne, M. H., Black, B. A., \& Lickteig, C. W. (2003). Research observations and lessons learned for the Future Combat Systems (ARI Research Product 2003-04). Alexandria, VA: U.S. Army Research Institute for the Behavioral and Social Sciences.

Campbell, C. H., Quinkert, K. A., \& Burnside B. L. (2000). Training for performance: The structured training approach (ARI Special Report 45). Alexandria, VA: U.S. Army Research Institute for the Behavioral and Social Sciences.

Carnahan, T. J., Lickteig, C. W., Sanders, W. R., \& Durlach, P. J. (2004). Novice versus expert command groups: Preliminary findings and training implications for future combat systems (ARI Research Report 1821). Alexandria, VA: U.S. Army Research Institute for the Behavioral and Social Sciences.

Conduct-of-Fire Trainer. (2003). Available: http://www.globalsecurity.org/military/library/ policy/army/fm/17-12-7/ch4.htm

Department of the Army, Headquarters. (2002, August 1). Objective Force maneuver units of action (TRADOC Pamphlet 525-3-90). Fort Monroe, VA: U.S. Army Training and Doctrine Command.

Department of the Army, Headquarters. (2003a, August). Mission command (FM 6-0). Washington, DC: Author.

Department of the Army. (2003b, April 14). Operational requirements document for the Future Combat Systems (Change 3, JROC Approved). Fort Knox, KY: Unit of Action Maneuver Battle Lab.

G. \& C. Merriam Company. (1961). Webster's new international dictionary of the English language, 2nd edition, unabridged. Cambridge, MA: The Riverside Press.

Gossman, J. R., Flynn, M. R., \& Breidenbach, M. E. (2004). Prototype electronic training support package for the Future Force (CD-ROM available from Dr. Billy Burnside, U.S. Army Research Institute, Armored Forces Research Unit, ATTN: DAPE-ARI-IK (Bldg. 2423), Fort Knox, KY 40121).

Lickteig, C. W., Sanders, W. R., Durlach, P. J., Lussier, J. W., \& Carnahan, T. J. (2003). Human performance essential to battle command: Report on four future combat systems command and control (FCS $C^{2}$ ) experiments (ARI Research Report 1812). Alexandria, VA: U.S. Army Research Institute for the Behavioral and Social Sciences. 
Odierno, R. T. (2004). Army unmanned aerial vehicle (UAV) systems: A cost-effective combat multiplier. Association of the United States Army. Available: http://www.ausa.org/ PDFdocs/UAVS.pdf.

OneSAF Objective System. (2004). Available: http://www.onesaf.org/onesaf.html.

Reilly, G. D. (1997). Battlefield visualization: "We can't get there from here" (Monograph). Fort Leavenworth, KS: School of Advanced Military Studies, U.S. Army Command and General Staff College.

Sanders, W. R. (2003). Applying cognitive science principles to digital systems training (ARI Research Report). Alexandria, VA: U. S. Army Research Institute for the Behavioral and Social Sciences.

Solick, R. E., Spiegel, D. K., Lussier, J. W., \& Keene, S. D. (1997). Visualization and judgmental forecasting of simulated duties (ARI Research Note 97-08). Alexandria, VA: U.S. Army Research Institute for the Behavioral and Social Sciences.

Throne, M. H. \& Burnside, B. L. (2002). Integrated training and performance support for the Objective Force (ARI Research Report 1801). Alexandria, VA: U.S. Army Research Institute for the Behavioral and Social Sciences.

Tiron, R. (2001). War urgency drives decisions on deployments of U.S. drones. Defense News Magazine. Available: http://www.nationaldefensemagazine.org/article.cfm?Id=680.

U.S. Army Research Institute for the Behavioral and Social Sciences (ARI). (2003). Battle command visualization 101 (BCV 101). (Statement of Work). Alexandria, VA: Author. (Available from U.S. Army Research Institute, Armored Forces Research Unit, ATTN: DAPE-ARI-IK (Bldg. 2423), Fort Knox, KY 40121.)

West, C. K., Farmer, J. A., \& Wolff, P. M. (1991). Instructional design implications from cognitive science. Needham Heights, MA: Allyn and Bacon. 


\section{Appendix A}

Acronyms

\begin{tabular}{|c|c|}
\hline AAR & After Action Review \\
\hline AGM & Attack Guidance Matrix \\
\hline $\mathrm{AO}$ & Area of Operation \\
\hline ARI & U.S. Army Research Institute for the Behavioral and Social Sciences \\
\hline $\mathrm{BCV}$ & Battle Command Visualization \\
\hline BDA & Battle Damage Assessment \\
\hline$C^{2}$ & Command and Control \\
\hline $\mathrm{C}^{4} \mathrm{ISR}$ & $\begin{array}{l}\text { Command, Control, Communications, Computers, Intelligence, Surveillance, and } \\
\text { Reconnaissance }\end{array}$ \\
\hline CCIR & Commander's Critical Information Requirements \\
\hline CECOM & Communications-Electronics Command \\
\hline COFT & Conduct-of-Fire Trainer \\
\hline COP & Common Operational Picture \\
\hline CSE & Commander Support Environment \\
\hline $\mathrm{DA}$ & Department of the Army \\
\hline DARPA & Defense Advanced Research Projects Agency \\
\hline DIS & Distributed Interactive Simulation \\
\hline $\mathrm{EO} / \mathrm{IR}$ & Electro-Optical/Infrared \\
\hline FBC & Future Battlefield Conditions \\
\hline FCS & Future Combat Systems \\
\hline FM & Field Manual \\
\hline HPT & High Pay-Off Target \\
\hline HTR & Human Target Recognition \\
\hline IFV & Infantry Fighting Vehicle \\
\hline INFOSYS & Information Systems \\
\hline ISR & Intelligence, Surveillance, and Reconnaissance \\
\hline KPP & Key Performance Parameter \\
\hline LMS & Learning Management System \\
\hline
\end{tabular}


M\&D C ${ }^{2} \quad$ Multi-Cell and Dismounted Command and Control

METT-TC Mission, Enemy, Troops, Terrain, Time, and Civilian Considerations

MTI Moving Target Indicator

NAI Named Area of Interest

NTC National Training Center

OneSAF One Semi-Automated Force

OTB OneSAF Test Bed Baseline

OOS

One Semi-Automated Forces (OneSAF) Objective System

PEO Program Executive Office

PIR Priority Intelligence Requests

POI Program of Instruction

R\&S Reconnaissance and Surveillance

ROZ Restricted Operating Zone

SAR Synthetic Aperture Radar

STO Science \& Technology Objective

STRI Simulation, Training and Instrumentation

TRADOC U.S. Army Training and Doctrine Command

TTP Tactics, Techniques, and Procedures

UAV Unmanned Air Vehicle

UGS Unmanned Ground System

UGV Unmanned Ground Vehicle

WIMP Windows, Icons, Menus, and Pull Downs 


\section{Appendix B}

\section{Prototype Program of Instruction}

B-1 


\section{Battle Command Visualization 101: PROTOTYPE PROGRAM OF INSTRUCTION}

\section{Introduction}

Purpose

The U.S. Army has a future force battle command goal of enabling dominant maneuver through combined arms operations. Dominant maneuver requires that future leaders and Soldiers be able to "see first" which requires, among other things, the application of technologically superior sensor capabilities to a well thought-out reconnaissance and surveillance (R\&S) plan. The purpose of this prototype training program is to provide small unit commanders the technical and tactical skills to employ and exploit networked sensors and help meet the "see first" objective. This training program provides basic or introductory training as the first requisite to battle command visualization (BCV). Visualization in a battle command context is the common operational picture (COP) presentation of knowledge derived from information and intelligence that leads to an understanding of the situation.

Background

Future battle command will be executed through a multi-layered, robust command, control, communications, and computer $\left(\mathrm{C}^{4}\right)$ network that is enabled by multiplatform/multi-functional intelligence, surveillance, and reconnaissance (ISR) systems. These ISR systems will include space-based, airborne, and ground-based sensors mounted on manned and unmanned systems. It is anticipated that all combat units will have organic sensors as well as the ability to receive information from other external sensors. Future leaders employing these sensors must quickly be able to make sense of the information that is being provided to them, especially if they are viewing the raw information output of these systems before it is fused with other sources of information and presented as part of the COP. They also need to understand the limitations and vulnerabilities of these systems so that they do not have unrealistic expectations about sensor performance. By fully exploiting the capabilities of organic and external sensors and compensating for their limitations and vulnerabilities, future leaders and Soldiers will be able to "See First" which will allow them to begin to understand the enemy's future actions and what they will need to do to defeat those actions.

Future leaders and Soldiers will have much of their battle command training delivered through their C4 and ISR systems that have a training environment, performance support systems, and automated performance feedback embedded within them. The training environment will seamlessly integrate live, virtual, and constructive training that supports the training of future leaders on demand, anywhere or anytime. 


\section{Introduction, continued}

\begin{tabular}{|c|c|}
\hline Approach & $\begin{array}{l}\text { This BCV } 101 \text { instruction will be delivered by interactive courseware that is } \\
\text { embedded into the FCS Command and Control }\left(C^{2}\right) \text { and R\&S training environment } \\
\text { or other media. The sequencing of the training anticipates that participants first } \\
\text { understand the capabilities of the command and control system or sensor operator } \\
\text { control unit in which this training will be embedded, as well as the operational } \\
\text { characteristics and limitations of their unit's organic R\&S sensors and the enemy's } \\
\text { capability to either destroy or deceive the sensor. The participants will then } \\
\text { participate in individual instruction delivered by interactive courseware that } \\
\text { contains all of the materials required for the learner to master the included lessons. } \\
\text { They will learn and practice the needed skills, building from basic to more complex } \\
\text { requirements. Feedback will be provided in the context of the learned material. } \\
\text { Sometimes, it will be presented immediately during exercise performance; at other } \\
\text { times, feedback will be delayed until after an exercise to permit the learner to } \\
\text { identify performance deficiencies. }\end{array}$ \\
\hline & $\begin{array}{l}\text { The program follows the structured training approach, wherein all exercises have } \\
\text { clearly defined tasks, conditions, standards, and specific feedback. }\end{array}$ \\
\hline $\begin{array}{l}\text { Training } \\
\text { description }\end{array}$ & $\begin{array}{l}\text { This POI describes a set of four training modules. This individual training is } \\
\text { directed at Soldiers in the Company or Troop Command Group. The modules are: } \\
\text { - Module 1: Sensor Capabilities, Limitations, and Vulnerabilities } \\
\text { - Module 2: Sensor Tasking } \\
\text { - Module 3: Dynamic Sensor Retasking } \\
\text { - Module 4: Sensor Integration into Tactical Operations }\end{array}$ \\
\hline $\begin{array}{l}\text { Training } \\
\text { participants }\end{array}$ & $\begin{array}{l}\text { The primary training audience is the Company or Troop Headquarters which may } \\
\text { include: the Commander, Executive Officer, First Sergeant, Platoon Leaders, } \\
\text { Platoon Sergeants, and the Fires and Effects Non-Commissioned Officer. } \\
\text { Additional training audience participants may include brigade and battalion } \\
\text { commanders, staff members, and future force leaders who plan R\&S operations or } \\
\text { view raw sensor outputs. Robotics or Sensor Operators assigned to the Company or } \\
\text { Troop Headquarters are not considered part of the training audience for this } \\
\text { program since they will have received comparable training during their advanced } \\
\text { individual military occupational specialty qualification course. }\end{array}$ \\
\hline $\begin{array}{l}\text { Training } \\
\text { prerequisites }\end{array}$ & $\begin{array}{l}\text { Members of the Company or Troop Headquarters are expected to be proficient in } \\
\text { the operation of the Future Combat System (FCS) Battle Command system in which } \\
\text { this training program will be embedded. They should also be familiar with their } \\
\text { unit's tables of organization and equipment, including the types and numbers of } \\
\text { organic sensor systems; the types, numbers, and capabilities of external sensors that } \\
\text { may be made available to them; and troop leading procedures at the company or } \\
\text { troop level, which include R\&S planning. }\end{array}$ \\
\hline
\end{tabular}




\section{Introduction, continued}

Training objectives

Hours of Training Time (Estimates)
Specific training objectives for the levels are shown in the separate sections of this Program of Instruction (POI) which address each one in detail. The desired end state for the training includes several overarching goals. The training audience members will be able to:

- Demonstrate the capabilities, limitations, and vulnerabilities of their unit's organic R\&S sensors, as well as the external sensors that may be made available to them;

- Given an enemy target set, select the appropriate sensor or sensor payload to employ based on weather, terrain, and other information;

- Adjust sensor employment strategies based on analysis of sensor outputs, other ISR cues, and the tactical situation; and

- Plan the employment of the unit's organic R\&S sensors, using the FCS C4ISR system to meet the commander's priority intelligence requirements. The plan should be synchronized with higher headquarters' R\&S plans to exploit the information provided by external sensors.

TBD - The amount of time required to execute this POI will depend upon the project team's analysis of the developed full set of training levels after it has been implemented in the DARPA/CECOM FCS C2 Training Environment at ARI-Fort Knox.

\section{Overview of the Training Modules}

\section{General}

The modules have been designed using the M1 Tank Conduct-of-Fire Trainer (COFT) as a model. Like the COFT, the BCV 101 POI places the participants in a realistic tactical situation and presents them with a full range of simulation-based exercises that vary in target type and number, target motion, visibility, and other complex conditions. The result will be challenging, progressive visualization training.

The training participants are expected to have already completed their individual training on the operation of the FCS C2 system. It is also anticipated there will be an embedded Learning Management System (LMS) to track Soldier participation and performance during the training. The program has also been designed so that an instructor will not be required to facilitate the training. Intelligent tutors will be embedded into the interactive courseware to the extent that technology supports this concept. Participants will also have access to an internet portal that will allow them to reach sensor subject matter experts for assistance if they need additional support beyond that provided by the courseware.

All training will be done in a tactical context with the participants working with R\&S tasking matrices and overlays appropriate to their organization. They will also be provided the CCIR and PIR upon which the unit R\&S plan is based. Where required, they will also be provided with intelligence summaries and IPB products such as a Modified Combined Obstacle Overlay to assist them in determining the appropriate sensor to use for a given condition. 


\section{Overview of the Training Modules, continued}

BCV 101

Training

Exercises

Training Progression
The BCV 101 POI, when fully developed, contains a structured training exercise library designed to train visualization skills. The following figure represents the potential structured exercises library that could be created for BCV 101 .

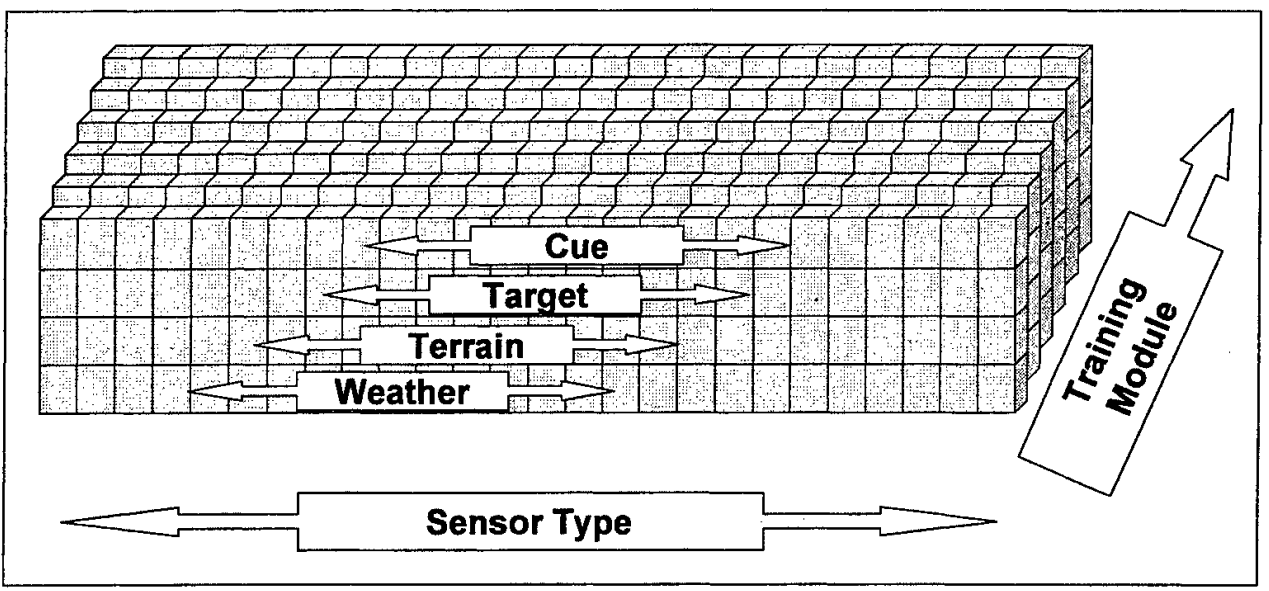

Figure B-1. BCV 101 Training Exercise Matrix.

The number of exercises that would be created depends on a number of factors. For example, there are 13 types of future force sensors, a minimum of two weather types (optimal, sub-optimal), three types of terrain (open, close, urban), 10 target conditions (based on type, number, activity, and countermeasures), and two types of cues (detected, predicted). This could result in a potential library of 1,560 structured exercises if just a single version was created for each possible combination of factors.

After completing a series of progressively more complex exercises in a module, the participant will be required to successfully complete a gate exercise that will test the participant's mastery of the material. If the participant successfully completes the exercise, the BCV 101 training program software will pass the qualification score to the LMS and allow the participant to continue with the training. If the participant does not successfully complete the gate exercise, the BCV 101 training program software will determine the areas in which the participant needs additional training and will present additional training exercises for practice. Once the participant has completed those exercises, the BCV 101 training program will again present a gate exercise. If the participant does not successfully complete the second gate exercise, then the BCV 101 training program software will alert the BCV 101 training coordinator who will analyze the participant performance and recommend additional training. 


\section{Training Modules Specifications}

Module 1:

Sensor capabilities, limitations, and vulnerabilities
Purpose: To train the participants on their unit's organic sensor capabilities, limitations, and vulnerabilities, as well as the external sensors that may be made available to them.

Approach: The participants will log into the LMS embedded into the FCS C2 system. Based on duty position, they will then be directed to the interactive courseware for their unit's organic sensor system type for the rest of the training.

Initially, the participant will be given a pre-test to determine his or her understanding of the subject matter. If the participant scores at an acceptable level, the participant will be directed to Module 2. If the participant's score does not meet standard, then the participant will begin Module 1.

The participant will be shown a series of informational pages, pictures, animations, and simulations that will cover the capabilities, limitations, and vulnerabilities for each system. Where appropriate they will be provided TTPs on the employment of various systems. Specific information covered during this training will include the effects of weather and terrain on the sensor. Participants will also be trained on the methods that enemy forces can be expected to use to destroy sensors, spoof them, or negate their capabilities.

As the participant progresses through the training, there will be automated checks on learning to assess participant comprehension, such as presenting tactical situations with various weather, terrain, and enemy conditions and asking the participants to select the appropriate sensor. The participant could also be asked to identify raw sensor images and determine which sensor provided the image. The participant could also be provided degraded sensor images and asked to identify changes to the sensor payload or mission tasking (such as altitude, speed, sensor payload orientation) that could improve the quality of the image. The interactive courseware will provide immediate feedback to the participant.

If the participant is not progressing satisfactorily through the training, the courseware will direct the participant to additional resources that can provide additional information about the sensors. After demonstrating sufficient mastery of sensor capabilities, limitations, and vulnerabilities, the participant will be directed to Module 2. 


\section{Training Modules Specifications, continued}

Module 2:

Sensor Tasking
Purpose: To train participants to task organic unit sensors to gain information to answer the commander's critical information requirements (CCIR) and Priority Intelligence Requests (PIR). The participants will also be trained to identify CCIR and PIR that are beyond the capabilities of their unit's organic capabilities and to initiate requests for information to higher headquarters to obtain support from external sensors to provide the needed support.

Approach: The participants will be trained using a series of exercises that build on the expertise gained through completing the Module 1 training. The participants will be provided a tactical framework, including the higher unit's R\&S plan and overlay, CCIRs and PIRs and intelligence summaries. A visual projection of the location of all friendly forces based on the COP will be available. They will also be provided their unit's R\&S tasking matrix that has been completed except for the designation of the sensor that will be employed to answer the CCIR/PIR. The matrix is designed so that each successive task becomes more complex through manipulation of weather, terrain, the target type, the availability of sensors, and the ambiguity of the enemy situation.

To answer each PIR, the participant will be required to select from a list of possible sensor taskings that provide the sensor's mission profile (speed, altitude, sensor payload, sensor payload orientation, and other pertinent information). Once the participant selects a sensor, the interactive courseware will provide a simulation of the sensor tasking and provide the appropriate sensor output for that selection. If the participant has made the adequate selection, the desired information will be displayed. If the participant has made an inadequate selection, the participant will be provided additional feedback as to why that selection was incorrect and then required to make another selection. This process will be repeated until all of the pre-designated PIR elements have been covered.

Initially, the participant will be selecting taskings for individual sensors. Later in the module, the participant will be required to select among multiple combinations of sensors to answer the CCIR/PIR. As the participant progresses through the training, the amount of feedback or coaching that is being presented for an incorrect selection will be reduced so that by the end of the training level the participants have to determine where they made an error without outside assistance.

The embedded LMS will track participant performance. If the performance warrants, the student will be referred back to Module 1, for refresher training, directed to repeat designated Module 2 exercises, or permitted to move on to Module 3 training. 


\section{Training Modules Specifications, continued}

Module 3: Dynamic Sensor Retasking

Module 4: Sensor Integration into Tactical Operations
Purpose: To train the participants to dynamically retask organic unit or external higher-headquarters sensors based on changing METT-TC factors.

Approach: The participants, building upon their mastery of the Module 2 training, will be expected to dynamically retask sensors during a series of increasingly complex exercises in which there is a dynamic friendly and enemy situation. Their sensor retasking will be expected to answer time-sensitive CCIR/PIRs. The participant is provided the higher unit's ISR plan and overlay, CCIRs and PIRs, and intelligence summaries. The location of all friendly and detected enemy forces will be displayed on a visual projection of the COP. Initially, the participant will be executing an R\&S tasking matrix in which the sensor tasking has already been developed. During the course of task execution, the participant will be provided additional information which will cause the participant to change the sensor tasking.

As the participant progresses through the module, the number of sensors that the participant will have to retask will increase, the potential vulnerability of the sensors to enemy action will increase, the amount of information provided about the enemy will decrease, and the amount of time between the retasking directive from the participant's commander until the enemy situational information is expected to be presented will be decreased.

During this module, the participant will not be provided feedback about performance until the time has expired for the collection of enemy information. The feedback presented will focus on whether the enemy information in the exercise has been detected (i.e., 5 of 5 enemy tanks located), whether sensors were lost because their vulnerability to enemy action had not been considered, and whether the most efficient choice for retasking sensors was made based on the tactical situation. A solution to the exercise will be presented. The participant will be required to execute similar exercises until the required level of performance is obtained. The embedded LMS will track participant performance. If the performance warrants, the student will be referred back to Module 2 for refresher training or permitted to move on to Module 4 training.

\section{[Note: This module will not be developed by the BCV Project Team]}

Purpose: To train the participants to integrate organic unit-level sensors and available higher headquarters sensors into ISR operations.

Approach: The participants, adding to their mastery of Module 3 training, will be expected to plan and execute a series of ISR operations, primarily focused on organic unit-level sensors and available higher headquarters sensor support. They will develop an ISR plan that includes an R\&S tasking matrix and an R\&S overlay to gain information to support the CCIR/PIR. The participants will then execute the ISR plan, making adjustments to sensor taskings based on an evolving enemy and friendly situation. Participant performance will be graded based on the amount of information that is obtained from the ISR plan and the efficiency of the operation in terms of whether the sensor tasking obtained the desired information (more information is better), number of sensors required to obtain the information (fewer is better), the number of sensor losses due to enemy activity (fewer is better), and the amount of time required to answer the CCIR/PIR (shorter is better). 


\section{Training Modules Specifications, continued}

Module 4: As the participant progresses through the training, the ISR tasks become

Sensor increasingly complex based on the tactical situation. For example, the initial Integration into Tactical Operations (continued) operation might be an attack against a defending enemy located in open terrain. Subsequent operations may include moving enemy forces, complex terrain such as jungles or forests, and urban operations. The embedded LMS will track participant performance. If the performance warrants, the student will be referred back to Module 2 or 3 for refresher training. At the successful completion of the training, the participant's training record will be annotated by the LMS and an appropriate training certificate issued.

\section{Training Support Materials}

Module 1

Sensor Capabilities, Limitations, and Vulnerabilities materials include a listing of the sensors to be trained; a schedule of the training flow; participant training guides, either paper-based or electronic-based; embedded simulation files with augmented sensor cues as required; participant performance measurement metrics; participant performance examples; and demonstration of participant performance.

Module 2

Sensor Tasking materials include a description of the training exercises contained in the level; simulation system files; participant training guides; the supporting tactical materials including CCIR/PIRs, R\&S tasking matrixes and overlays, and intelligence summaries as appropriate. Participant performance measurement metrics and performance examples are also required.

Module 3

Dynamic Sensor Retasking materials include a description of the training exercises contained in the level; simulation system files; participant training guides; the supporting tactical materials including CCIR/PIRs, R\&S tasking matrixes and overlays, ISR graphics, and intelligence summaries as appropriate. Participant performance measurement metrics and performance examples are also required.

Module 4

Sensor Integration into Tactical Operations materials include a description of the training exercises contained in the level; simulation system files; participant training guides; the supporting tactical materials including CCIR/PIRs, R\&S tasking matrixes, ISR graphics, and intelligence summaries as appropriate. Participant performance measurement metrics and performance examples are also required. 


\section{Module 1 Training Details}

Overview

Exercise
Depending on the combat unit of assignment, the participant may be responsible for planning the employment of various sensor platforms that may include three types of Unmanned Air Vehicles (UAVs), three types of Unmanned Ground Vehicles (UGVs), and five types of unattended ground systems (UGSs). The UAVs and UGVs can be equipped with various combinations of sensor payloads. The participant may also be required to exploit the raw information that is provided by external sensors, such as those from a higher headquarters. The Module 1 training will have to address each of these systems and their payloads.

An upfront demonstration of individual Soldier performance related to understanding sensor capabilities and limitations and the Soldier's role in tasking/controlling sensors during tactical operations may also be included in this level.

A description of a representative exercise for Module 1 training follows.

Task: Participant selects the most appropriate UAV sensor.

Condition:

- Participant is provided with the following information

- a COP that has the locations of all friendly units and the locations of enemy units that have been detected

- an R\&S overlay with a target area of interest

- it is night and there is atmospheric haze in the operational area

- the operational area has rolling terrain with numerous forested hills along with agricultural fields

- there is no battlefield clutter in the target area of interest

- Participant provided with an intelligence report that indicates multiple enemy tactical vehicles have been reported moving along a major highway toward the target area of interest

- Participant can choose among microUAVs equipped with electro-optical and infrared sensors and Shadow 200 UAVs equipped with SAR or MTI sensor packages

- The target area of interest is within range of both the microUAV and the Shadow 200 UAV

- Participant is required to select the most appropriate UAV sensor/package to detect the moving tactical enemy vehicles.

Standard: Participant selects the right UAV and sensor package.

Performance Feedback: After the participant makes a selection, the training program provides immediate feedback on whether the selection was right or wrong. If the selection was wrong, the participant is provided the reason the selection was incorrect and then provided an opportunity to try again to select the best sensor. Once the participant has selected the right sensor, then simulation associated with the training program shows the sensor flying a route with the orientation and coverage of the sensor payload. As the sensor continues to fly, the training program provides information on the effects of weather and terrain on the sensor and sensor payload as well as showing the information that the sensor will be reporting. The participant is then presented another exercise to continue the training. 


\section{Module 2 Training Details}

Overview

Module 2

Exercise 1
Unit members have now completed the training on sensor capabilities, limitations, and vulnerabilities. That training prepared the participants to select, given an enemy target set, the appropriate sensor or sensor payload to employ based on weather, terrain, and other information.

Following are descriptions of two representative exercises for Module 2 training.

Task: Participant confirms intelligence report.

Condition:

- Participant provided with the following information

- a COP that has the locations of all friendly units and the locations of enemy units that have been detected

- an R\&S overlay with a target area of interest

- it is daylight with unrestricted vision

- there is no battlefield clutter in the target area of interest

- Participant provided with an intelligence report that indicates a single, stationary DRAEGA has been reported in the target area of interest; the location has been given to within 100 meters

- Participant has tasking authority for microUAVs equipped with electro-optical and infrared sensor and Shadow 200 UAVs equipped with SAR and MTI sensor packages

- The target area of interest is within range of both the microUAV and the Shadow 200 UAV

- Based on the conditions presented, the participant has to select from a menu the best combination of sensor, sensor payload, and route to confirm the intelligence report.

Standard: Participant selects the best UAV, sensor, and route, based on conditions, to confirm report.

Performance Feedback: After the participant makes a selection, the sensor route, the orientation and coverage of the sensor payload is displayed on the FCS C2 system's COP. If the selection was correct, the stationary DRAEGA is displayed. The participant is then given credit for properly tasking the sensor and the score is reported to the learning management system. The participant is then provided a more complex exercise. If the selection was incorrect, the sensor route, the orientation, and the coverage of the sensor payload are displayed along with the correct location of the stationary DRAEGA and a description of why the selection was incorrect for the conditions. The participant is then presented another exercise with similar conditions to continue the training. 


\section{Module 2 Training Details, continued}

Module 2

Exercise 2
Task: Participant confirms intelligence report.

Condition:

- Participant provided with the following information

- a COP that has the locations of all friendly units and the locations of enemy units that have been detected (enemy units have short range anti-aircraft guns)

- an R\&S overlay with a target area of interest

- it is daylight with unrestricted vision

- there is no battlefield clutter in the target area of interest

- Participant provided with an intelligence report that indicates a single, stationary DRAEGA has been reported in the target area of interest; the location has been given to within 1000 meters

- Participant has tasking authority for microUAVs equipped with electro-optical and infrared sensor and Shadow 200 UAVs equipped with SAR and MTI sensor packages

- The target area of interest is within range of both the microUAV and the Shadow 200 UAV

- Based on the conditions presented, the participant has to select from a menu the best combination of sensor, sensor payload, and route to confirm the intelligence report.

Standard: Participant selects the best UAV, sensor, and route, based on conditions, to confirm report.

Performance Feedback: After the participant makes a selection, the sensor route, the orientation and coverage of the sensor payload is displayed on the FCS C2 system's COP. If the selection was correct, the stationary DRAEGA is displayed. The participant is then given credit for properly tasking the sensor and the score is reported to the learning management system. The participant is then provided a more complex exercise. If the selection was incorrect, the sensor route, the orientation, and the coverage of the sensor payload are displayed along with the correct location of the stationary DRAEGA and a description of why the selection was incorrect for the conditions. The participant is then presented another exercise with similar conditions to continue the training. 


\section{Module 3 Training Details}

Overview

Module 3 Exercise
After completing Module 2, participants will be trained to adjust their sensor employment strategies based on analysis of sensor outputs, other ISR cues, and the tactical situation. The adjustments to the sensor strategies should exploit the information that organic and external sensors and other systems are providing to the participant.

A description of a representative exercise for Module 3 training follows.

Task: Participant retasks sensors to locate high pay-off target.

Condition:

- Participant's unit is in contact with enemy forces

- Participant provided with the following information

- a COP that has the locations of all friendly units and the locations of enemy units that have been detected (enemy units have short range anti-aircraft guns)

- an R\&S overlay with target area of interest

- it is daylight with unrestricted vision

- there is battlefield clutter in the area of operation

- Participant has tasking authority for microUAVs equipped with electro-optical and infrared sensor and Shadow 200 UAVs equipped with SAR and MTI sensor packages

- Participant is monitoring the execution of the sensor taskings required by his unit's R\&S plan

- Participant provided with an intelligence report that indicates a high pay-off target (HPT) may be located in an area that is not being covered by sensors. The HPT is in a four square kilometer area, may or may not be moving, and may or may not be camouflaged

- Participant's commander wants to continue some sensor coverage required by the R\&S plan to support maneuver against enemy forces

- Based on the conditions presented, the participant has to select from a menu the best retasking combination of sensor, sensor payload, and route to locate the HPT as well as continue to support current tactical operations.

Standard: Participant selects the best retasking option based on the situation.

Performance Feedback: After the participant makes a selection, the sensor route, the orientation and coverage of the various sensors being monitored and controlled by the participant is displayed by the training program on the FCS C2 system's COP. If the selection was correct, the HPT is displayed. The participant is then given credit for properly retasking sensors and the score is reported to the learning management system. The participant is then provided another complex exercise. If the selection was incorrect, the sensor route, the orientation, and the coverage of the sensor payload are displayed along with the correct location of the stationary DRAEGA and a description of why the selection was incorrect for the conditions. The participant is then presented another exercise with similar conditions to continue the training. 


\section{Module 4 Training Details}

Overview

After completing Module 3, participants will be trained to plan the employment of the unit's organic R\&S sensors, using the FCS C2 system, to meet the commander's priority intelligence requirements. They will also be trained to synchronize the unit plan with higher headquarters' R\&S plans to exploit the capabilities of external sensors.

[Note: The Project Team will not be developing this training module] 


\section{Appendix C}

\section{Training Matrix}

Exercises 1 through 7 are saved in a single file titled: BCV_101_Ex1to7 in both Red OneSAF Testbed Baseline (OTB) and Commander Support Environment (CSE) \#1. All tasks are expected to have the identification and verification of the enemy vehicle within one minute of the microUAV taking its picture.

Bundle 1

\begin{tabular}{|c|c|c|c|c|c|}
\hline Exercise & Task & $\begin{array}{c}\text { Unmanned } \\
\text { Aerial Vehicle }\end{array}$ & $\begin{array}{c}\text { Named Area of } \\
\text { Interest }\end{array}$ & $\begin{array}{c}\text { Target Type and } \\
\text { Condition }\end{array}$ & Target Grid \\
\hline 1 & $\begin{array}{c}\text { Confirm cooperative } \\
\text { cueing and outputs }\end{array}$ & $\begin{array}{c}1 \text { Shadow 200 } \\
1 \text { microUAV }\end{array}$ & NAI N1 & $\begin{array}{c}1 \text { Stationary } \\
\text { Draega }\end{array}$ & 591171 \\
\hline 2 & $\begin{array}{c}\text { Confirm cooperative } \\
\text { cueing and outputs }\end{array}$ & $\begin{array}{c}1 \text { Shadow 200 } \\
1 \text { microUAV }\end{array}$ & NAI N1 & $\begin{array}{c}1 \text { Stationary } \\
\text { GARM }\end{array}$ & 596168 \\
\hline 3 & $\begin{array}{c}\text { Confirm cooperative } \\
\text { cueing and outputs }\end{array}$ & $\begin{array}{c}1 \text { Shadow 200 } \\
1 \text { microUAV }\end{array}$ & NAI N1 & $\begin{array}{c}1 \text { Stationary } \\
\text { BRDM-AT }\end{array}$ & 592163 \\
\hline 4 & $\begin{array}{c}\text { Identify and report, } \\
\text { confirming SAR } \\
\text { detections }\end{array}$ & $\begin{array}{c}1 \text { Shadow 200 } \\
1 \text { microUAV }\end{array}$ & NAI N2 & $\begin{array}{c}1 \text { Stationary } \\
\text { Draega }\end{array}$ & 573131 \\
\hline 5 & $\begin{array}{c}\text { Identify and report, } \\
\text { confirming SAR } \\
\text { detections }\end{array}$ & $\begin{array}{c}1 \text { Shadow 200 } \\
1 \text { microUAV }\end{array}$ & NAI N2 & $\begin{array}{c}1 \text { Stationary } \\
\text { BRDM }\end{array}$ & 583123 \\
\hline 6 & $\begin{array}{c}\text { Identify and report, } \\
\text { confirming SAR } \\
\text { detections }\end{array}$ & $\begin{array}{c}1 \text { Shadow 200 } \\
1 \text { microUAV }\end{array}$ & NAI N2 & $\begin{array}{c}1 \text { Stationary } \\
\text { Draega }\end{array}$ & 588112 \\
\hline 7 & $\begin{array}{c}\text { Identify and report, } \\
\text { confirming SAR } \\
\text { detections }\end{array}$ & $\begin{array}{c}1 \text { Shadow 200 } \\
1 \text { microUAV }\end{array}$ & NAl N3 & $\begin{array}{c}\text { 1 Draega } \\
1 \text { Garm } \\
1 \text { Darya } \\
\text { Stationary }\end{array}$ & $\begin{array}{c}543148 \\
538155\end{array}$ \\
\hline
\end{tabular}


Exercises 8 through 11 are saved in a single file titled: BCV_101_Ex8to11 in both Red OTB and CSE \#1. All tasks are expected to have the identification and verification of the enemy vehicle within one minute of the microUAV taking its picture.

Bundle 2

\begin{tabular}{|c|c|c|c|c|c|}
\hline Exercise & Task & $\begin{array}{l}\text { Unmanned } \\
\text { Aerial Vehicle }\end{array}$ & $\begin{array}{c}\text { Named Area of } \\
\text { Interest }\end{array}$ & $\begin{array}{l}\text { Target Type and } \\
\text { Condition }\end{array}$ & Target Grid \\
\hline 8 & $\begin{array}{l}\text { Confirm templated } \\
\text { enemy assembly } \\
\text { area }\end{array}$ & $\begin{array}{l}1 \text { Shadow } 200 \\
1 \text { microUAV }\end{array}$ & NAI N8 & $\begin{array}{l}\text { Stationary Draegas, } \\
\text { Garms, Ural trucks }\end{array}$ & $\begin{array}{l}565230- \\
585230- \\
565200- \\
585195\end{array}$ \\
\hline 9 & $\begin{array}{l}\text { Detect and confirm } \\
\text { intel report of an } \\
\text { enemy formation }\end{array}$ & $\begin{array}{c}1 \mathrm{~A}-160(\mathrm{MTI}) \\
1 \text { Shadow } 200 \\
1 \text { microUAV }\end{array}$ & NAI N9 & $\begin{array}{c}\text { Moving Draegas, } \\
\text { GARM }\end{array}$ & $\begin{array}{l}537263 \text { to } \\
554257 \text { to } \\
563205\end{array}$ \\
\hline 10 & $\begin{array}{l}\text { Detect and confirm } \\
\text { intel report of an } \\
\text { enemy column }\end{array}$ & $\begin{array}{c}1 \text { A-160 (MTI) } \\
1 \text { Shadow } 200 \\
1 \text { microUAV }\end{array}$ & NAI N10 & $\begin{array}{c}\text { Moving Draegas, } \\
\text { Grams, BRDMs }\end{array}$ & $\begin{array}{l}515219 \text { to } \\
450220\end{array}$ \\
\hline 11 & $\begin{array}{l}\text { Detect and confirm } \\
\text { intel report }\end{array}$ & $\begin{array}{l}1 \text { Shadow } 200 \\
1 \text { microUAV }\end{array}$ & NAI N11 & $\begin{array}{l}1 \text { Stationary, dug-in } \\
\text { or camouflaged } \\
\text { Purga }\end{array}$ & 460250 \\
\hline
\end{tabular}


Exercises 12 through 14 are saved in a single file titled: BCV_101_Ex12to14 in both Red OTB and CSE \#1. All tasks are expected to have the identification and verification of the enemy vehicle within one minute of the microUAV taking its picture.

Bundle 3

\begin{tabular}{|c|c|c|c|c|c|}
\hline Exercise & Task & $\begin{array}{l}\text { Unmanned } \\
\text { Aerial Vehicle }\end{array}$ & $\begin{array}{c}\text { Named Area } \\
\text { of Interest }\end{array}$ & $\begin{array}{l}\text { Target Type and } \\
\text { Condition }\end{array}$ & Target Grid \\
\hline 12 & $\begin{array}{c}\text { Confirm } \\
\text { templated } \\
\text { enemy positions }\end{array}$ & $\begin{array}{c}1 \text { A-160 (SAR) } \\
1 \text { Shadow } 200 \\
1 \text { microUAV }\end{array}$ & $\begin{array}{c}\text { NAl N12: } \\
2816-3421- \\
3721-3718- \\
3434-3014- \\
2815\end{array}$ & $\begin{array}{c}\text { Stationary, dug-in } \\
\text { or camouflaged } 2 \\
\text { Draegas, } 2 \\
\text { Garms, } 2 \text { Purgas; } \\
\text { Civilian vehicles } \\
\text { present }\end{array}$ & $\begin{array}{c}\text { Draegas: } \\
\text { 2881514796, } \\
\text { 3382117645; } \\
\text { Garms: } \\
\text { 3077716123, } \\
\text { 3479420436; } \\
\text { Purgas: } \\
\text { 3585919078, } \\
2936415357\end{array}$ \\
\hline 13 & $\begin{array}{l}\text { Confirm intel } \\
\text { reports and } \\
\text { templated } \\
\text { enemy positions }\end{array}$ & $\begin{array}{l}1 \text { Shadow } 200 \\
1 \text { microUAV }\end{array}$ & $\begin{array}{c}\text { NAI N13: } \\
\text { 4115-4513- } \\
4410-4010- \\
3911\end{array}$ & $\begin{array}{c}\text { Stationary, dug-in } \\
\text { or camouflaged } 3 \\
\text { GARMs, } 2 \text { BRDM- } \\
\text { ATs, } 4 \\
\text { dismounted } \\
\text { infantry squads; } \\
\text { Civilian vehicles } \\
\text { present }\end{array}$ & $\begin{array}{c}\text { Garms: } \\
\text { 4056112951, } \\
3972711601 \\
\text { 4133910814; } \\
\text { BRDM-ATs: } \\
\text { 4087014028, } \\
\text { 4333512211; } \\
\text { Dismounted Inf: } \\
3987712464 \\
4010211292 \\
4089913907 \\
4122710215\end{array}$ \\
\hline 14 & $\begin{array}{l}\text { Confirm intel } \\
\text { report of } \\
\text { company-size } \\
\text { Assembly Area }\end{array}$ & $\begin{array}{l}1 \text { Shadow } 200 \\
1 \text { microUAV }\end{array}$ & NAI N14 & $\begin{array}{c}3 \text { Stationary } \\
\text { Draegas, } 3 \\
\text { Garms, } 2 \text { Ural } \\
\text { trucks; Civilian } \\
\text { vehicles present }\end{array}$ & $\begin{array}{c}\text { Draegas: } \\
3748007932, \\
3747207852, \\
3759607888 ; \\
\text { Garms: } \\
3785707605, \\
3785007525, \\
\text { 378790743; Ural } \\
\text { trucks: } 3759607794, \\
\text { 3795907547 }\end{array}$ \\
\hline
\end{tabular}


Exercises 15 through 18 are saved in a single file titled: BCV_101_Ex15to18 in both Red OTB and CSE \#1. All tasks are expected to have the identification and verification of the enemy vehicle within one minute of the microUAV taking its picture.

Bundle 4

\begin{tabular}{|c|c|c|c|c|c|}
\hline Exercise & Task & $\begin{array}{l}\text { Unmanned } \\
\text { Aerial Vehicle }\end{array}$ & $\begin{array}{c}\text { Named Area } \\
\text { of Interest }\end{array}$ & $\begin{array}{l}\text { Target Type and } \\
\text { Condition }\end{array}$ & Target Grid \\
\hline 15 & $\begin{array}{c}\text { Confirm intel } \\
\text { report of a } \\
\text { moving } \\
\text { company sized } \\
\text { unit }\end{array}$ & $\begin{array}{l}1 \text { Shadow } 200 \\
1 \text { microUAV }\end{array}$ & NAI N15 & $\begin{array}{c}6 \text { Moving Garms, } \\
3 \text { BRDM-ATs; } \\
\text { Civilian vehicles } \\
\text { present }\end{array}$ & $\begin{array}{l}\text {.. Garms: } \\
5402212590, \\
5417712617, \\
5428712628, \\
5439712639, \\
5478912672, \\
5488812672, \\
5498112683 ; \\
\text { BRDM-ATs: } \\
5451312650, \\
5459612661, \\
5468412661\end{array}$ \\
\hline 16 & $\begin{array}{l}\text { Confirm } \\
\text { template } \\
\text { position of } \\
\text { artillery unit in } \\
\text { firing position }\end{array}$ & $\begin{array}{l}1 \text { Shadow } 200 \\
1 \text { microUAV }\end{array}$ & NAI N16 & $\begin{array}{c}\text { Stationary, in } \\
\text { firing position, } 5 \\
\text { Purgas, } 5 \text { Ural } \\
\text { trucks }\end{array}$ & $\begin{array}{c}\text { Purgas: } \\
4950016322, \\
5034615916, \\
4946615341, \\
5021016931, \\
4926317370 ; \text { Ural } \\
\text { trucks: } 4942717377, \\
5030216933 \\
4958016328, \\
5041415925 \\
4954115349 \\
\end{array}$ \\
\hline 17 & $\begin{array}{c}\text { Confirm intel } \\
\text { report of } \\
\text { tactically moving } \\
\text { mixed formation }\end{array}$ & $\begin{array}{l}1 \text { Shadow } 200 \\
1 \text { microUAV }\end{array}$ & NAI N17 & $\begin{array}{c}1 \text { Moving } \\
\text { Draega, } 2 \\
\text { Garms, } 3 \\
\text { BRDMs }\end{array}$ & $\begin{array}{c}\text { Draega: } \\
\text { 3662307099; } \\
\text { Garms: } \\
\text { 3675007412, } \\
\text { 3646207319; } \\
\text { BRDMs: } \\
\text { 3664007640, } \\
\text { 3635207564; } \\
\text { BRDM-AT: } \\
\text { 3654707454 }\end{array}$ \\
\hline 18 & $\begin{array}{c}\text { Confirm intel } \\
\text { report of a } \\
\text { tactically moving } \\
\text { formation }\end{array}$ & $\begin{array}{l}1 \text { Shadow } 200 \\
1 \text { microUAV }\end{array}$ & NAI N18 & $\begin{array}{l}3 \text { Moving BRDM- } \\
\text { Recons, } 3 \text { Orels; } \\
\text { Civilian vehicles } \\
\text { present }\end{array}$ & $\begin{array}{c}\text { BRDM-Recons: } \\
3213107426, \\
3240507443, \\
3250807212 ; \text { Orels: } \\
3318707160 \\
3342707400 \\
3369306920\end{array}$ \\
\hline
\end{tabular}


Exercises 19 and 20 are saved in a single file titled: BCV_101_Ex19to20 in both Red OTB and CSE \#1. All tasks are expected to have the identification and verification of the enemy vehicle within one minute of the microUAV taking its picture.

Bundle 5

\begin{tabular}{|c|c|c|c|c|c|}
\hline Exercise & Task & $\begin{array}{l}\text { Unmanned } \\
\text { Aerial Vehicle }\end{array}$ & $\begin{array}{c}\text { Named Area } \\
\text { of Interest }\end{array}$ & $\begin{array}{l}\text { Target Type and } \\
\text { Condition }\end{array}$ & Target Grid \\
\hline 19 & $\begin{array}{l}\text { Detect, identify } \\
\text { and confirm } \\
\text { multiple intel } \\
\text { reports of } \\
\text { stationary and } \\
\text { moving enemy } \\
\text { formations }\end{array}$ & $\begin{array}{c}1 \mathrm{~A}-160(\mathrm{MTI}) \\
1 \mathrm{~A}-160 \text { (SAR) } \\
1 \text { Shadow } 200 \\
3 \text { microUAV }\end{array}$ & Multiple NAls & $\begin{array}{c}3 \text { Draegas, } 3 \\
\text { Garms, } 1 \text { Purga, } \\
1 \text { Darya, } 1 \\
\text { BRDM-Recon, } 1 \\
\text { BRDM-AT, 3Ural } \\
\text { trucks, } 3 \text { MTLBs }\end{array}$ & $\begin{array}{c}\text { Draegas: } \\
3977788385, \\
3930495387, \\
\text { 3659792309; } \\
\text { Garms: } \\
\text { 4113088013, } \\
\text { 3808694542, } \\
\text { 3747789772; Purga: } \\
\text { 3226787573; Darya: } \\
\text { 3064494034; } \\
\text { BRDM-Recon: } \\
\text { 4552898398; } \\
\text { BRDM-AT: } \\
\text { 4745698499; Ural } \\
\text { trucks: } \\
\text { 4725398127, } \\
\text { 4099587336; } \\
\text { 3057693764; } \\
\text { MTLBs: } \\
2790492309, \\
2746492546, \\
2702492783\end{array}$ \\
\hline 20 & $\begin{array}{l}\text { Detect, identify } \\
\text { and confirm } \\
\text { multiple intel } \\
\text { reports of } \\
\text { stationary and } \\
\text { moving enemy } \\
\text { formations }\end{array}$ & $\begin{array}{c}1 \text { A-160 (MTI) } \\
1 \text { A-160 (SAR) } \\
1 \text { Shadow } 200 \\
3 \text { microUAV }\end{array}$ & Multiple NAls & $\begin{array}{c}3 \text { Draegas, } 2 \\
\text { Garms, } 1 \text { Purga, } \\
1 \text { SA-13, } 2 \\
\text { Darvas, } 3 \\
\text { BRDM-Recons, } \\
1 \text { URAL truck }\end{array}$ & $\begin{array}{c}\text { Draegas: } \\
\text { 3483800525; } \\
3262902716, \\
\text { 2992804681; } \\
\text { Garms: } \\
\text { 3536799789, } \\
\text { 3094803849; Purga: } \\
\text { 2599901281; SA-13: } \\
\text { 2465398070; } \\
\text { Daryas: } \\
\text { 2586200129; } \\
\text { 2888498655; } \\
\text { BRDM-Recon: } \\
\text { 3976601451; } \\
\text { 4057899543, } \\
\text { 3564908562; URAL } \\
\text { truck: } 3517699789\end{array}$ \\
\hline
\end{tabular}

